Foundations and Trends ${ }^{\circledR}$ in

Microeconomics

Vol. 6, No. 1 (2010) 1-97

(C) 2011 B. M. S. Van Praag and A. Ferrer-i-Carbonell

DOI: $10.1561 / 0700000026$

\title{
Happiness Economics: A New Road to Measuring and Comparing Happiness
}

\author{
By Bernard M. S. Van Praag and \\ Ada Ferrer-i-Carbonell
}

\section{Contents}

1 Introduction 2

1.1 What is Happiness? 2

1.2 The Attitude of Mainstream Economics
Toward Happiness

2 Happiness: Methods of Analysis 10

2.1 Question Modes 10

2.2 Methods of Secondary Analysis 11

3 Life Satisfaction, Happiness 16

4 Domain Satisfactions $\quad 20$

4.1 Job Satisfaction 21

4.2 Financial Satisfaction 25

4.3 Health Satisfaction 30

5 Cardinal or Ordinal? $\quad 37$ 
6 Aggregating Domain Satisfactions to Life Satisfaction

7 Leyden School

8 Reference Groups

9 Memory, Anticipation and Adaptation

15 The Significance of Happiness Economics for Normative Economics

16 Concluding Observations, Research and Applications for the Future 
Foundations and Trends ${ }^{\circledR}$ in

Microeconomics

Vol. 6, No. 1 (2010) 1-97

(C) 2011 B. M. S. Van Praag and A. Ferrer-i-Carbonell

DOI: $10.1561 / 0700000026$

\title{
Happiness Economics: A New Road to Measuring and Comparing Happiness
}

\author{
Bernard M. S. Van Praag ${ }^{1}$ and \\ Ada Ferrer-i-Carbonell ${ }^{2}$ \\ 1 University of Amsterdam, The Netherlands, b.m.s.vanpraag@uva.nl \\ 2 Universitat Autònoma de Barcelona,Spain, ada.ferrer@iae.csic.es
}

\begin{abstract}
This paper deals with the concept of happiness in economics. Of late there has come into life a branch of happiness economics and it is this field that will be our concern. Actually, not only economists are interested in quantifications of happiness but also researchers in other disciplines. Notably there are several psychologists who investigate happiness as well. We mention Schimmack et al. (2002), Kahneman et al. (1999, 2006), Kahneman and Krueger (2006), Clark et al. (2008) and Lucas and Schimmack (2009). There are also some interconnections between happiness economists and psychologists as in the citations just mentioned. In this paper we will focus on happiness economics, although we will sometimes refer to work in other disciplines as well. Happiness economics is up to now an empirically oriented field. There is no attention for philosophical contemplations on happiness, the sense of life, etc. as we find in philosophy and religious studies (see, e.g., Feldman (2010), Nussbaum and Sen (1993), Haybron (2010) and Bok (2010) for a philosophical approach). We shall not touch on these issues in this tract.
\end{abstract}




\section{1}

\section{Introduction}

\subsection{What is Happiness?}

Economic science deals with individual behavior, notably the decisions of individuals dealing with questions like what do they buy, what do they produce, how long do they work, how do they spend their leisure time, whom do they choose as partner in marriage, and so on. The basic explanation among economists and non-economists alike is that individuals do not act haphazardly, but with a specific objective in mind. They try to optimize or improve their situation. If a situation $A$ is considered to be better than situation $B$, we say that the individual derives more well-being or happiness from $A$ than from $B$. There are philosophers (e.g., Haybron, 2010), who distinguish between the two words well-being and happiness as standing for two different concepts. However, the problem is that at an empirical level nobody can make out what is the exact difference between the two concepts. For instance, it is very hard to conceive of two situations where one is happier in $B$ than in $A$, but derives more well-being from $A$ than from $B$. If the two words would stand for different properties of $A$ and $B$, then giving 'more well being' seems to go parallel with causing 'more happiness'. In short, we and most happiness economists make no semantic differ- 
ences between the two. Other terms used to refer to this concept are utility, ophelimity, eudaemonia and satisfaction. We shall take them all as operationally synonymous. That is, we do not exclude the possibility that it is philosophically or psychologically possible to give different meanings to the terms, but it is empirically imposible yet with our present day empirical instruments of observation to make a meaningful differentiation between them.

This paper deals with the concept of happiness in economics. Of late there has come into life a branch of happiness economics and it is this field that will be our concern. Actually, not only economists are interested in quantifications of happiness but also researchers in other disciplines. Notably there are several psychologists who investigate happiness as well. We mention Schimmack et al. (2002), Kahneman et al. (1999, 2006), Kahneman and Krueger (2006), Clark et al. (2008) and Lucas and Schimmack (2009). There are also some interconnections between happiness economists and psychologists as in the citations just mentioned. In this paper, we will focus on happiness economics, although we will sometimes refer to work in other disciplines as well. Happiness economics is up to now an empirically oriented field. There is no attention for philosophical contemplations on happiness, the sense of life, etc. as we find in philosophy and religious studies (see, e.g., Feldman, 2010; Nussbaum and Sen, 1993; Haybron, 2010; Bok, 2010, for a philosophical approach). We shall not touch on these issues in this tract.

\subsection{The Attitude of Mainstream Economics Toward Happiness}

Most economists until recently were very suspicious about happiness economics. Actually, the common opinion in the twentieth century was that happiness is not empirically measurable, and consequently, all empirical studies about it could not be different from worthless. And if some concept is believed to be non-measurable, even theoretical studies about happiness would not be possible as the basic ingredient was a chimera. It is evident that we are not of that opinion, for, if so, writing this study would make no sense. Actually there is now a growing body 
of serious economists who are willing, either reluctantly or wholeheartedly, to include happiness economics as a part of economic science. Nevertheless, not only for describing the historical setting, but also for a better understanding of happiness economics itself, we devote a few pages to the viewpoint of mainstream economics, as it reigned in the twentieth century, and as it still reigns in a shrinking majority group of present day economists.

It is possible to describe human behavior in simple mathematical terms. We describe situations by some dimensions we deem relevant, say, variables $X_{1}, X_{2}, \ldots$. For instance, let us take the traditional example of consumer theory. We think of the consumption bundle of the individual in terms of goods and services bought. A specific situation is then described by having $x_{1}$ units of bread, $x_{2}$ bottles of beer, etc. The happiness derived from a specific bundle $x=\left(x_{1}, x_{2}, \ldots\right)$ is set equal to a number $U(x)$ and behavior is described as choosing that situation from the set of reachable situations, which maximizes $U(x)$. Usually it is assumed that 'reachable' stands for those bundles that may be bought for an amount of money $M$ and prices $p=\left(p_{1}, p_{2}, \ldots\right)$.

In the nineteenth century, economists (like Edgeworth, 1881) had the idea that the function $U(x)$ would be known in the near future, leading to the situation that consumer behavior of rational utility maximizing consumers could be rather well predicted and even corrected, if it was non-optimal. The economist/sociologist Pareto (1909) made it clear in his influential Manuel dÉconomie Politique that things were more complicated than that. Let us assume for convenience that $U\left(x_{1}, x_{2}\right)=x_{1}^{2}+x_{2}^{2}$ which is maximized under the budget constraint $x_{1}+2 x_{2}=10, x_{1}, x_{2}>0$. This yields an optimal consumption bundle or demand vector. However, we see that maximization of $\tilde{U}\left(x_{1}, x_{2}\right)=\sqrt{x_{1}^{2}+x_{2}^{2}}$ would yield the same optimum. Actually, each $\tilde{U}\left(x_{1}, x_{2}\right)=\phi\left(U\left(x_{1}, x_{2}\right)\right)$ where $\phi(U(\cdot))$ is a monotonously increasing function will yield the same optimum. Hence, observing choice behavior does not give sufficient information to detect the utility function in the background that is maximized. Or said more precisely, there is an infinite class of utility functions, which yield the same choice behavior. It is therefore that we speak of an ordinal utility concept. What do the ordinal utility functions belonging to one class have in common? These 
are the so-called utility indifference curves, where an indifference curve is the whole set of points given by the equation $U\left(x_{1}, x_{2}\right)=u$, where $u$ is a constant. They can be discovered by observing the demand behavior when the budget constraint is varying, say, by varying income $M$ and the price vector $p$ in the variable budget $p_{1} x_{1}+p_{2} x_{2}=M$. Hence, the fact is that the common indifference curves can in theory be detected or identified by looking at choice behavior, even if in reality this method is rather difficult to apply as there is not much price variation in most consumer surveys. However, by this method we are unable to detect the specific utility function used by the individual, because there is a multitude of so-called cardinal utility functions yielding the same empirical choice behavior. There is no one-one relationship between the observed choice behavior and the underlying utility function yielding the observed behavior.

This fact, first explicitly signaled by Pareto, changed the progress of economic science in the twentieth century. The influential tract $A n$ Essay on the Nature and Significance of Economic Science by Robbins $(1932,1938)$ gave a final blow to the idea of cardinal utility. Debreu (1959), Houthakker (1950) and Samuelson (1947, 1974) established a new structure of economic science in which the utility concept (cardinal but even ordinal) was factually eliminated. One of the main instruments of which one had great expectations, the utility function, lost much of its position, as it could not be empirically identified for individuals. This is not to say, of course, that individuals do not have some cardinal utility function in mind when performing choices between alternatives, but it cannot be estimated from their choice behavior.

Since Pareto's work, the measurement of utility fell into disgrace. Not only was observation of demand behavior shown to be insufficient to derive the individual's cardinal utility/happiness function, but knowledge of cardinal utility appeared also unnecessary to make welfare judgments or to predict behavior. A utility function became just a description of a preference ordering or rather of a net of indifference curves, losing all its classical meaning of describing levels of pleasure. Therefore, looking for an alternative source of measurement became unnecessary. Since Pareto and especially since the publication of Lionel Robbins' influential tract in 1932 most mainstream economists 
were mainly preoccupied on minimizing the necessary assumptions to describe human behavior and welfare economics was left with income as the only measure to compare well-being between individuals.

In the previous lines we chose consumer behavior as our playground, but the same holds for all situations of choice, e.g., when choosing between jobs, or between marriage partners.

Nevertheless, this strong result on the non-measurability of utility or happiness is also very unsatisfactory. In common language, people speak about 'John being very happy lately', and happiness is compared between individuals, e.g., 'John is much happier than Peter'. This suggests that individuals are able to measure the level of happiness of people, including their own happiness, and that individuals are able to make interpersonal comparisons of happiness. Obviously, the exactness of such measurements has to be taken with a grain of salt and the measurement outcomes will fluctuate over time and circumstances, but there is no reason why everyday statements by almost every individual would have no basis at all. The point is also clearly visible when we think on the definition of poverty. If poverty is a status of low well-being and we pretend that we can recognize individuals as being 'poor', then it implies that some kind of measurement of well-being is possible. For instance, if the poverty line for a family of four persons is set by Parliament at $€ 1200$ per month, it suggests strongly that the well-being that may be derived from an amount below $€ 1200$ per month is considered too low in the specific country.

Could it be that cardinal well-being after all is measurable, but that the instrument which economics used thus far, observation of choice behavior, is not the right instrument of observation? Despite the logical positivism that has dominated economics since the 1930s, some economists walked against the stream and did look for alternatives to the measurement of utility by asking individuals themselves about the satisfaction level they are experiencing or which happiness values they would assign to hypothetical situations. The simplest question of this type is given in Figure 1.1

This is what we may call the direct approach to happiness measurement. Although intuitively this seems an obvious way to get information, there are social scientists that doubt the validity of such a 


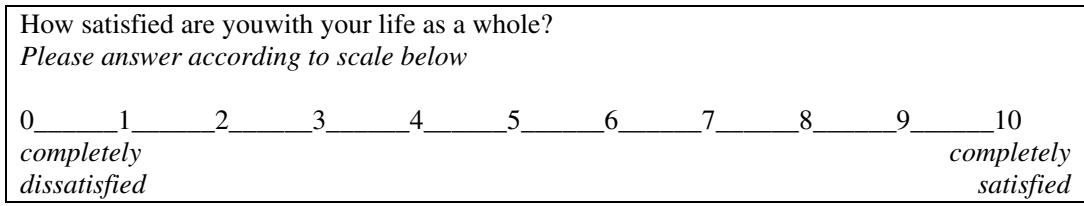

Fig. 1.1 Life satisfaction question.

question. However, at the moment question modules of this type have been posed to millions of individuals all over the globe, and it is seen that the great majority of respondents has no problem whatsoever to answer on this question and it has also been seen that most people in the same objective circumstances evaluate their life approximately by the same figure. This question is the prototype of the happiness questions, which form the basic instrument for all studies in happiness economics.

The same question can be posed to individuals with respect to specific aspects/domains of their life, e.g., their financial situation, their health, their marriage life, the satisfaction with their job, etc. Then we speak of domain satisfactions.

There are basically two ways to study data sets in general and happiness in particular. The first is so-called primary analysis. This is just a matter of tabulating and counting to get answers on the question what fraction of the population under consideration is happy and what fraction is unhappy, mostly differentiated with respect to relevant subsets, e.g., age brackets, income brackets, or education segments. So-called secondary analysis goes further. It tries to find out why individuals feel happy or less happy, it is a quest for the determining factors that cause happiness, or as econometricians say, the explanatory variables. In this paper we shall focus in line with the economic literature on the secondary analysis.

The direct approach to happiness measures relies on the assumption that self-reported satisfaction can be used as a proxy measure for utility. For economists, the most obvious way to test this assumption is to examine whether individual behavior can be explained or predicted by the individual's reported happiness. Up to this time and to our knowledge, there are only a very few studies that have tried 
to do this. We mention Kapteyn et al. (1979) that tried to do just that on the basis of the direct approach to utility measurement. Their outcome was that in the context of consumer behavior the assumption that consumers maximized their utility had to be firmly rejected. Actually, they came out with much more support for so-called 'satisficing' behavior. This term, coined by Simon (1955), stands for behavior that tries to maintain the status quo, except if satisfaction falls behind a critical level, in which case the individual tries to find a better position. According to Wikipedia 'satisficing is a decision-making strategy that attempts to meet criteria for adequacy, rather than to identify an optimal solution. A satisficing strategy may often be (near) optimal if the costs of the decision-making process itself, such as the cost of obtaining complete information, are considered in the outcome calculus (see also Schwartz et al., 2002; Frijters, 2000). Clark (2001) shows that reported job satisfaction can predict future job quits while controlling for a set of job characteristics; Guven et al. (2010) find that the satisfaction gap between spouses explains the probability of a future divorce; Oswald et al. (2009) find a positive causal correlation between happiness reports and individuals' productivity in a laboratory setting; and Helliwell (2007) finds a negative correlation between the probability to committ suicide and self-reported life satisfaction. From a somewhat different perspective, Oswald and Wu (2011) correlate subjective measures of happiness with a market-derived indicator of quality of life (i.e., behavior observed in the market). They find a very strong correlation between reported happiness of one million US individuals and an objective measure of regional quality of life.

Other scientists have sustained the meaningfulness of satisfaction measures by reporting positive correlations between reported happiness and physical expressions such as amount of smiling in the questionnaire (Sandvik et al., 1993), changes in facial muscles (Kahneman, 1999), and physical measures of brain activity (Urry et al., 2004); or by proving that individuals can predict each others' reported happiness levels (Diener and Lucas, 1999; Sandvik et al., 1993).

In Section 2 we start by considering the methods of analysis in happiness economics. In Section 3 we consider life satisfaction (or happiness), in Section 4 we consider domain satisfactions, in Section 5 we 
return to the ordinality-cardinality question, and in Section 6 we lay the link between domain satisfactions and satisfaction with life as a whole. In Section 7 we consider the work of the Leyden school that may be seen as a forerunner of modern happiness economics. In Section 8 we consider the effect of the individual's reference group on her his happiness. In Section 9 we consider what we can say about the influence of past events and the anticipated future on present life satisfaction. In Section 10 we deal with the effect of climate and more generally of the external environment on satisfaction. In Section 11 we consider the effect of inequality on individual happiness and we consider happiness inequality per se. In Section 12 we consider in how far the vignette approach, so popular in marketing, can be applied in happiness economics. In Section 13 we try to delineate the significance of happiness economics for normative economics. In Section 14 we draw some conclusions and discuss the relevance of the new findings for economic science and the social sciences in general.

There is nowadays an enormous production of papers in happiness economics, and the reader will understand that it is unfeasible to do justice to all contributions. Moreover, the task of reading would become rather tedious for the reader of this tract who wants a short introduction into the field. We mention here a few recent monographs that give introductions to the field. Not only are they sometimes more detailed than ours, but they have rather different outlooks and accents as well. We mention a.o. Frey and Stutzer (2002), Layard (2005), Frey (2008), Graham (2009), Bok (2010), Van Praag and Ferrer-i-Carbonell (2004, 2008). 


\subsection{Question Modes}

As already said the question module in Figure 1.1 ("How satisfied are you with your life as a whole?") will be interpreted by most respondents as asking 'how happy are you?' The somewhat less emotional detached wording 'satisfied' instead of 'happy' is chosen as some respondents may have different emotional interpretations of the word 'happy'. Obviously, the $0-10$-scale is not sacrosanct. There are versions with a $1-7$-scale or even a 1-3-scale. Clearly, the coarser the scale, the less information will be conveyed by the respondent. However, a too fine scale may lead to a confusing seemingly exactness, because respondents are not able to respond to this type of questions with too much accuracy. It is wellknown that respondents are subject to moods that vary over the day. Hence, there is a natural variation in the response, when the question is asked repeatedly to the same person. What we are aiming for is the general average and this is the way in which the responses are interpreted. If one likes to get an idea of these variations depending on mood, you might add to the above question 'satisfied at this moment or the last half hour'. The psychologists Kahneman et al. (2004) have developed a method called the Day Reconstruction Method (DRM) 
by means of which they collect data per period of 20 minutes that reconstructs the daily experiences of the respondents during the day. This method can be seen as an alternative to the well-being questions and has also been used by other researchers (White and Dolan, 2009). For cost reasons and the selectivity introduced because many people will not be willing to make this effort, there are only a very few surveys using this method.

Actually, the idea of using numerical answers was not the popular version 10 years ago. In older versions, still in usage, the response categories are cast in verbal terms, like "Very happy", "Happy", "Not very Happy", "Not happy at all", or "Fully satisfied", "Rather satisfied", "Both yes and no", "Less than satisfied", "Not at all satisfied". The reason was that survey designers were afraid that respondents would be unable to answer on a numerical scale. This fear may be dispelled by now. The general feeling among researchers is that the outcomes of these numerical questions are generally comparable.

Finally, we mention that in the future it is very probable that discrete response categories will become old-fashioned as well. If we ask a person to answer by crossing a point on a line segment, where the left endpoint stands for 'completely unhappy' and the right endpoint for 'completely happy', we have in fact a continuous response scale. This mode has been used experimentally in Van Praag (1991). Nowadays, it would not be difficult to implement this continuous response scale in a computerized survey setting.

\subsection{Methods of Secondary Analysis}

Before we look at specific empirical results we have to devote some lines on the different estimation methods in use. The secondary analysis of happiness data is hampered by the fact that responses are nearly always categorical or discrete. Moreover, there is an ongoing debate on the interpretation of those data. Do they have cardinal significance or only ordinal significance? Apart from the two now frequently used methods we look after some alternative methods, recently introduced by Van Praag and Ferrer-i-Carbonell (2004) but already used by a.o. Luechinger (2009), Stevenson and Wolfers (2008c) and Pischke (2010). 
Whatever the specific categorization let us call the response by individual $n U_{n}$, where $U_{n}$ can assume, for instance, the values $0, \ldots, 10$ or $1, \ldots, 7$. If the response scale is verbal, it is still ordered from 'worst' to 'best' and the response categories may be translated into numbers. On the other hand we have a number of characteristics of the individual $n$, say $x_{1 n}, x_{2 n}, \ldots, x_{m n}$ of which we suspect that they might co-determine happiness. We may think of age, health status, family, income, job, etc.

The two most frequently used approaches are Ordinary Least Squares and Ordered Probit. OLS is obviously the easiest method and also intuitively most appealing. We assume a model equation

$$
U_{n}=\beta_{1} x_{1 n}+\cdots+\beta_{m} x_{m n}+\beta_{0}+\varepsilon_{n}
$$

The individual response by $n$ is influenced by a number of personal variables $x_{1 n}, x_{2 n}, \ldots, x_{m n}$. The effects $\beta$ reflect the size of the influence. If the effect is positive, it is happiness-increasing, if it is zero, there is no effect, and if it is negative, increasing the corresponding variable will reduce happiness. The trade-off between two dimensions is given by the equation $\beta_{1} \Delta x_{1}+\beta_{2} \Delta x_{2}=0$. For instance, if $x_{1}$ stands for income and $x_{2}$ for health status, then a deterioration in health by $\Delta x_{2}$ may be neutralized by an income increase of $\Delta x_{1}=\left(\beta_{2} / \beta_{1}\right) \Delta x_{2}$. We call the ratio $\left(\beta_{2} / \beta_{1}\right)$ the trade-off-ratio between income and health.

Actually, Equation (2.1) describes a satisfaction-indifference-hyperplane in the space $R^{m}$. Figure 2.1 shows a set of linear indifference curves in the income-health space. Each point $\left(x_{1 n}, x_{2 n}, \ldots, x_{m n}\right)$ stands for the description of the situation of a specific individual $n$. The planes are parallel where each level of happiness $U=0,1,2, \ldots, 10$ corresponds with a specific plane. Geometrically, the trade-off coefficients describe the slope coefficients of the plane.

The estimates $\beta$ are found by minimizing the sum of squared residuals

$$
S^{2}=\sum_{n=1}^{N}\left(U_{n}-\beta_{1} x_{1 n}+\cdots+\beta_{m} x_{m n}+\beta_{0}\right)^{2}
$$

The OP-approach is different. We may divide the sample or population in respondent subsets of 'most unhappy', 'rather unhappy', etc. according to the response categories, say $U=0,1,2, \ldots, 10$. The corresponding response fractions are $p_{0}, p_{1}, \ldots, p_{10}$. For example $1 \%$ of 


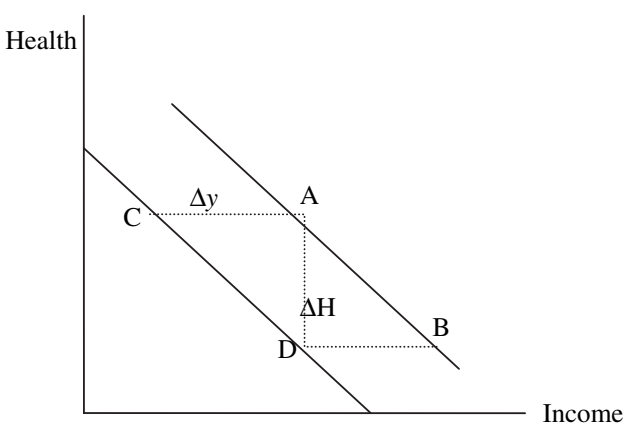

Fig. 2.1 Indifference curves, health-income.

the respondents is completely unhappy, that is $p_{0}=0.01,3 \%$ ranks itself in the category 1 , so $p_{1}=0.03$, and so on. The fractions evidently add up to $100 \%$. Similarly we define the cumulative fractions $P_{0}=0.01, P_{1}=p_{0}+p_{1}=0.01+0.03$ and so on. It implies that, e.g., $P_{6}$ is the fraction of the sample that is happy at level 6 or less. By construction the $P_{i}$ 's increase with happiness level $i$.

Now it is intuitively obvious that the chance on being happy or not depends on personal dimensions $x_{n}$. Hence, we may parameterize the $P$ 's as

$$
P_{i}(x)=F\left(\mu_{i} ; x, \beta\right), \quad i=1, \ldots, I
$$

where $F(\cdot)$ is a probability distribution and where $\mu_{i}$ is increasing in $i$. More specifically, it is frequently assumed that $F(\cdot)$ is a normal distribution function with expectation parameter $\beta_{1} x_{1}+\cdots+\beta_{m} x_{m}$ and variance equal to 1 .

We have

$$
P_{i}(x)=N\left(\mu_{i}-\beta^{\prime} x ; 0,1\right)
$$

We notice that $P_{i}(x)$ itself can be seen as a happiness indicator. Let us now define the latent variable

$$
u=\beta_{1} x_{1}+\cdots+\beta_{m} x_{m}+\varepsilon
$$

where the first term $\beta^{\prime} x$ is non-random and where $\varepsilon$ is a random error term with standard normal distribution. Then we have

$$
\begin{aligned}
P_{i}(x) & =P\left\{u \leq \mu_{i}\right\} \\
& =N\left(\mu_{i}-\beta^{\prime} x ; 0,1\right)
\end{aligned}
$$




\section{Happiness: Methods of Analysis}

The similarity between Equations (2.1) and (2.4) is of course striking. Indeed $u$ is also a happiness indicator. It is a monotonic transform of $P$ where $P$ assumes values on $[0,1]$ and $u$ on $(-\infty,+\infty)$. In both cases (2.1) and (2.4) the index may be decomposed into a non-random, i.e., structural part $\beta^{\prime} x$ and a random part $\varepsilon$.

In this case the effects $\beta$ are estimated by maximizing the loglikelihood of the sample, that is

$$
\mathscr{L}=\sum_{n=1}^{N} \ln \left(N\left(\mu_{i_{n}}-\beta^{\prime} x_{n}\right)-N\left(\mu_{i_{n}-1}-\beta^{\prime} x_{n}\right)\right)
$$

with respect to $\beta$ and $\mu$. Here $i_{n}$ is the response category to which respondent $n$ belongs, $\mu_{0}=-\infty, \mu_{I}=+\infty$, and there are $I$ response categories in total.

Notice that in this case $\beta^{\prime} x=u$ again describes the parallel indifference curves. If the two approaches are applied on the same responses to the same life satisfaction question it is logical that both estimation methods should produce the same net of indifference curves, that is, the same trade-off ratios, apart from statistical deviations. It follows then that $\beta_{\mathrm{OP}}=\gamma \times \beta_{\mathrm{OLS}}$, for some multiplying factor $\gamma$, where $\beta_{\mathrm{OP}}, \beta_{\mathrm{OLS}}$ stand for the corresponding OP- and OLS-estimates. The same is expected to hold for all other methods that estimate the trade-off ratios. This seems to be true indeed (see, e.g., Ferrer-iCarbonell and Frijters, 2004, Van Praag and Ferrer-i-Carbonell, 2004, 2008, Section 2).

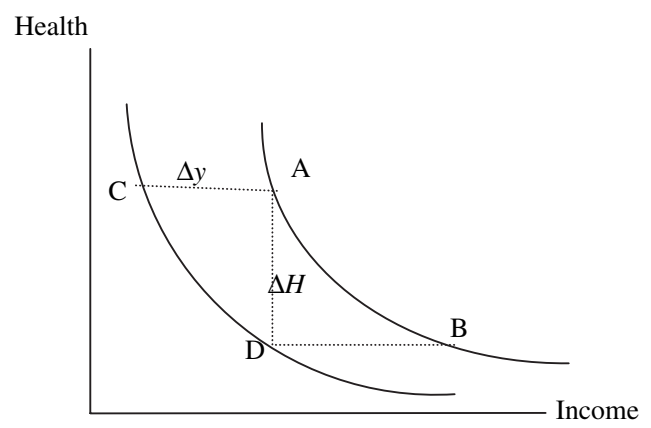

Fig. 2.2 Indifference curves, health-income. 
It follows that we do not have to be very anxious on which particular estimation method is used. If we want to estimate trade-off ratios, in nearly all cases all methods will yield approximately the same results except for a multiplication factor.

We notice that the linearity of the model is not so linear as we think. For instance, we may introduce next to a variable like age another variable $(a g e)^{2}$. In this way we may add non-linear features to the model. In Figure 2.2, we see a net of indifference curves after a nonlinear transformation of the variables Health and income. 


\section{Life Satisfaction, Happiness}

As said before, the literature abounds nowadays of happiness studies. More or less as an example we reproduce and comment on rather recent results, borrowed from Carol Graham (2009). Her results are not unique in the sense that many others have estimated similar equations, but they are interesting because her results demonstrate the general validity of the happiness approach. She estimated the same equation for the U.S., Latin-America and Russia (see Graham, pp. 52-54). We reproduce her results in Table 3.1.

The results are so attractive because they show that although there are differences between the three continents there is also a striking similarity. We notice that the variables are slightly differently defined for the three samples used by Graham. These differences were dictated by the fact that these were existing surveys for different objectives with a different setup. For a detailed description of the differences we refer to Graham (2009).

The first point to be noticed is the age effect. Nearly always the age effect is parabolic. When young people grow older their happiness reduces, until a minimum is reached between 40 and 50, and after that age happiness increases again. This age effect is found by many other 
Table 3.1. Life satisfaction equations estimated for three continents.

\begin{tabular}{|c|c|c|c|c|c|}
\hline \multicolumn{2}{|c|}{$\begin{array}{l}\text { Happiness in USA, } \\
1972-1998\end{array}$} & \multicolumn{2}{|c|}{$\begin{array}{l}\text { Happiness in Latin-America, } \\
2001\end{array}$} & \multicolumn{2}{|c|}{$\begin{array}{l}\text { Happiness in Russia, } \\
2000\end{array}$} \\
\hline Age & $-0.025^{* *}$ & Age & $-0.025^{* *}$ & Age & $-0.067^{* *}$ \\
\hline $\mathrm{Age}^{2}$ & $0.038^{* *}$ & $\mathrm{Age}^{2}$ & $0.000^{* *}$ & $\mathrm{Age}^{2}$ & $0.001^{* *}$ \\
\hline Male & $-0.199^{* *}$ & Male & -0.002 & Male & $0.152^{* *}$ \\
\hline Married & $0.775^{* *}$ & Married & $0.056^{*}$ & Married & 0.088 \\
\hline Log(income) & $0.163^{* *}$ & $\begin{array}{l}\log (\text { wealth } \\
\text { Index })\end{array}$ & $0.395^{* *}$ & $\begin{array}{l}\log \text { (equiv. } \\
\text { Income) }\end{array}$ & $0.389^{* *}$ \\
\hline Education & 0.007 & Yrs of education & -0.003 & $\begin{array}{l}\text { Level } \\
\quad \text { education }\end{array}$ & 0.015 \\
\hline Black & $-0.400^{* *}$ & Minority & $-0.083^{* *}$ & Minority & $0.172^{* *}$ \\
\hline Other than black & 0.049 & & & & \\
\hline Student & $0.291^{* *}$ & Student & 0.066 & Student & $0.199^{*}$ \\
\hline Retired & $0.291^{* *}$ & Retired & -0.005 & Retired & $-0.378^{* *}$ \\
\hline Housekeeper & $0.065^{*}$ & Homemaker & -0.053 & Housewife & 0.049 \\
\hline Unemployed & $-0.684^{* *}$ & Unemployed & $-0.485^{* *}$ & Unemployed & $-0.657^{* *}$ \\
\hline Self-employed & $0.098^{* *}$ & Self-employed & $-0.098^{* *}$ & $\begin{array}{l}\text { Self- } \\
\quad \text { employed }\end{array}$ & $0.537^{* *}$ \\
\hline Health & $0.623^{* *}$ & Self-report health & $0.468^{* *}$ & Health index & $0.446^{* *}$ \\
\hline Pseudo $R^{2}$ & 0.075 & Pseudo $R^{2}$ & 0.062 & Pseudo $R^{2}$ & 0.033 \\
\hline Number of obs. & 24128 & Number of obs. & 15209 & $\begin{array}{l}\text { Number of } \\
\text { obs. }\end{array}$ & 5134 \\
\hline
\end{tabular}

Note: ${ }^{* *}$ significance of $95 \%,{ }^{*}$ significance at $90 \%$.

Source: Graham (2009) Happiness around the World (pp. 52-54), Oxford University Press.

authors, where Blanchflower and Oswald (2007) were the first to establish this as a worldwide trend by comparing many countries. Males are happier than women in Russia, but less happy than women in the U.S. In Latin America the gender effect is virtually zero. The effect of income is always positive, but the size of the income effect differs quite considerably between the USA and Russia, being in Russia much larger than in the U.S. In Latin-America it proved to be difficult to measure household income accurately, as much of the income is 'informal' or in kind. Therefore researchers measured for Latin-America a correlate of income, a specific wealth index, based on an assessment by the interviewer of the household economic status and a long list of questions about ownership of goods and assets. The retired status in the USA is correlated with more happiness, while the retired in Russia are less happy than the workers. The unemployed status has a negative effect 
in each of the three continents. The most important effect appears to stem from the health variable.

The evidence seems overwhelming that the responses on happiness questions by individuals are not haphazard but that they really reflect the happiness level of the individuals. This may be derived from the fact that the effects just estimated make intuitively sense and from the fact that most of the effects are significantly different from zero. In short, we can find a definite underlying structure.

However, what we also see is that the structures between different cultures/countries may be similar in one sense and different in another sense. They are similar because in the three examples the same individual characteristics seem to affect individual happiness, but they are also different, as the numerical values of the estimated effects are widely different. Even sometimes the signs are different (cf. retirement). Clearly, these differences reflect the fact that there are different social structures in the various countries. For instance, the status of retirement of the Russian retiree is no cause for envy, while the American retiree is frequently in a comfortable position. The same may hold for the status of the self-employed. In Russia mostly successful (0.537), in Latin-America $(-0.098)$ not.

A second question point is the causality. Can we assume that individuals are happier because they have more income, or is it the other way round: happy individuals are mostly socially more adapted and therefore they get the better jobs and hence more income. It is very hard to find out the direction of the causality up to any degree of certainty. The same holds for the variable health. Are people feeling happier if they are healthier, or is a happy person feeling more healthy than an unhappy person? The same holds for the variables family size, marriage, etc. Most of the recent literature uses fixed effects estimators in order to account for individual personality traits, which means that the estimations are based on within-individual variations. Although this corrects for part of the causality problem to the extent that the individual's own personality determines both happiness and behavior, it does not solve the problem completely (Ferrer-i-Carbonell and Frijters, 2004). Stutzer and Frey (2006), for example, use a fixed effects estimator and find that happier individuals are more likely to get married, 
which presents no evidence that marriage makes people happier, but rahter that happier people have a larger chance to marry. In order to tackle the causality issues deeply one would need natural experiments or reliable instruments. Although dealing with the causality problem is gaining importance in the literature, this issue is yet far from being solved.

The causal relationship between income and happiness has been studied from various perspectives. Using lottery winnings, Gardner and Oswald (2007) and Kuhn et al. (2011) examine the causal effect of income on happiness. Since winning a lottery is not depending on the individual's characteristics (except that he is buying a lot), the causality problem is absent. If somebody is happier after winning the lottery, the direction of causality can only be from extra money to extra happiness. While the first authors find a positive effect of wining the lottery on happiness, the last ones found no effect of the lottery prize on reported happiness six months after wining. An important weakness of these studies is that it is uncertain whether the result says much about the causality between happiness and income in general. Using the German reunification as a natural experiment, Frijters et al. (2004) exploit the income increase in East German after the fall of the wall and conclude that income does have a positive causal effect on reported happiness. Pischke (2010) and Powdthavee (2010) use instead an instrumental variable approach. Pischke (2010) uses industry wage differentials as instruments for income and Powdthavee (2010) uses the proportion of household members with payslip information. The two authors find that income plays an important role on determining happiness, i.e., there is a positive causal effect of income on happiness.

The causality issue may, as the papers mentioned suggest, strongly affect the estimated coefficients and hence the estimated indifference curves. 


\section{Domain Satisfactions}

As said before there are several dimensions of life, like health, financial situation, social relations, family, housing, etc.; they are called life domains and just as we may ask for satisfaction with life as a whole we may ask individuals how satisfied they are with specific domains of life. Such questions can be analyzed in the same way as life satisfaction. When specifying on specific domains, it is obvious that such questions are easier to respond to. Asking for life satisfaction involves that respondents go into a thought process as: how satisfied I am with my marriage: very good and with my health: bad, and so on for other domains. After that we have to weigh off the different domains against each other in order to come to an overall evaluation. If we accept this thought model, it is understandable, why it is for most people much easier to evaluate a single aspect of life than life as a whole. The latter evaluation involves weighing different aspects against each other, while evaluating a specific domain is a much more monolithic activity. The result of domain satisfaction is also much less ambiguous than when we are evaluating life as a whole. Finally, the effect of variables on a domain satisfaction is in most cases rather straightforward. Consider for instance the effect of age. Older people will have more income than 
younger people, but their health will be less. It follows that their financial satisfaction will increase, due to their higher income. At the same time being older they are probably less healthy. Hence the effect of age is positive for financial satisfaction and negative for health satisfaction. If life satisfaction may be seen as the aggregate, it is unclear whether the age effect on life satisfaction will be positive or negative. This makes it advisable to look at domain satisfactions in their own right. Here we have a host of various domains, each with its own specific literature. We do not aim at completeness, but we will try to give a few illustrative examples.

\subsection{Job Satisfaction}

It is generally supposed that there is a link between how well workers function in their job and how satisfied they are with their work. This makes the concept of job satisfaction rather relevant for employers. Social scientists of different brands are and have been interested for a long time in the measurement of job satisfaction. We think primarily of psychologists, human resources managers, and labor economists. One of the first labor economists who studied the concept was Freeman (1978). The main question that is tapped for information is : "All in all how satisfied would you say you are with your job?": not at all/not too satisfied/somewhat satisfied/very satisfied. It is obvious that this question may be analyzed in a similar way as life satisfaction.

Here we shall consider, as an example, the estimated job satisfaction equation from Van Praag and Ferrer-i-Carbonell (2004, 2008a,b), Section 3. They look for determinants of job satisfaction by proposing a model equation of the type

$$
u_{n t}=\beta_{1} x_{1, n t}+\cdots+\beta_{m} x_{m, n t}+\gamma_{1} x_{1, n .}+\cdots+\gamma_{m} x_{m, n .}+\varepsilon_{n .}+\varepsilon_{n t}
$$

Here $u_{n t}$ stands for a satisfaction index, more precisely of individual $n$ in year $t, x_{k, n t}$ stands for the value of the explanatory variable $X_{k}$ of individual $n$ in year $t, x_{k, n}$. stands for the average value of the explanatory variable $X_{k}$ of individual $n$ over the period 1996-2001, the error variables $\varepsilon_{n}$. for a random fixed effect and $\varepsilon_{n t}$ for white noise, 
respectively. This is the so-called Mundlak (1978) specification. We estimated the Equation (4.1) by means of the Probit OLS-method, which was first proposed and applied in Van Praag and Ferrer-i-Carbonell $(2004,2008 \mathrm{a}, \mathrm{b})$. Here $u_{n t}$ is not cardinalized by the values $0,1, \ldots, 10$ as in the OLS-cardinalization but by so-called POLS-values.

The POLS-method attempts to do the same as the Ordered Probitmethod, based on a slightly simplified model. The philosophy behind the POLS-method is the following. Let us assume again that $P_{i}(x)=$ $N\left(\mu_{i}-\beta^{\prime} x ; 0,1\right)-N\left(\mu_{i-1}-\beta^{\prime} x ; 0,1\right)$, but that all $\beta$ 's are zero. Let the sample response fractions be $p_{0}, p_{1}, \ldots, p_{10}$, then the corresponding normal quantiles $\mu_{i}$ are defined by $N\left(\mu_{0}\right)=0, N\left(\mu_{1}\right)=p_{0}, N\left(\mu_{2}\right)=$ $p_{0}+p_{1}, \ldots, N\left(\mu_{11}\right)=1$, where $N(\cdot)$ stands for the normal distribution function. The corresponding best guesses for $u_{i}$ without further information on the $x$-values are then the conditional expectations

$$
u_{i}=E\left(u \mid \mu_{i-1}<u \leq \mu_{i}\right)=\frac{n\left(\mu_{i-1}\right)-n\left(\mu_{i}\right)}{N\left(\mu_{i}\right)-N\left(\mu_{i-1}\right)}
$$

The last equality is well-known from normal distribution theory (see, e.g., Maddala, 1983).

The POLS-method is now that the 'observations' $u_{i_{n}}$ are regressed on the explanatory variables $x_{n}$. As is demonstrated in Van Praag and Ferrer-i-Carbonell (2004, 2008a,b) the trade-off ratios derived by the POLS-method are nearly identical to the trade-off ratios derived by OLS or Ordered Probit estimation. The advantage of this method compared to OP is, that, when estimating panel data, the random fixed effect error structure is much easier implemented than with a similar model in the OP-framework. Comparing the OLS-cardinalization with the POLS-cardinalization, the latter is more flexible as it depends on the response distribution via the $p$ 's.

In Table 4.1 we reproduce here job satisfaction estimates for the UK (1996-1998), tapped from the British household Panel Survey (BHPS) (see also Freeman (1978), Pouliakas and Theodossiou (2010) for similar results).

Table 4.1 is an example of the equations that are estimated in the job satisfaction literature. We see that those estimates take into account 
Table 4.1. Job satisfaction UK, 1996-1998, POLS individual random effects.

\begin{tabular}{|c|c|c|}
\hline & Estimate & $t$-Ratio \\
\hline Constant & 11.070 & 9.330 \\
\hline Dummy for 1996 & -0.009 & -0.574 \\
\hline Dummy for 1997 & 0.017 & 1.142 \\
\hline Ln(age) & -7.323 & -11.297 \\
\hline$(\text { Ln }(\text { age }))^{2}$ & 1.162 & 12.556 \\
\hline Minimum age & 23 & \\
\hline Gender (male) & -0.465 & -4.159 \\
\hline Ln(household income) & 0.029 & 1.078 \\
\hline Ln(years education) & 0.008 & 0.068 \\
\hline Ln(adults) & -0.089 & -1.750 \\
\hline $\operatorname{Ln}($ children +1$)$ & -0.003 & -0.048 \\
\hline Living together & 0.128 & 5.048 \\
\hline $\operatorname{Ln}($ work income) & 0.416 & 4.768 \\
\hline $\operatorname{Ln}(\text { work income })^{*} \operatorname{Ln}($ age $)$ & -0.109 & -4.989 \\
\hline $\operatorname{Ln}(\text { work income })^{*} \operatorname{Ln}($ yrs education $)$ & -0.014 & -0.788 \\
\hline $\operatorname{Ln}(\text { work income })^{*}$ male & 0.053 & 3.266 \\
\hline Self-employed & 0.143 & 1.996 \\
\hline Ln(work hours) & -0.031 & -1.900 \\
\hline Ln(extra hours) & 0.029 & 3.437 \\
\hline Work at night & -0.119 & -1.961 \\
\hline Ln(hours household work) & -0.004 & -0.396 \\
\hline Mean (ln(household income)) & -0.041 & -1.140 \\
\hline Mean (ln(work income) $)$ & 0.006 & 0.434 \\
\hline Mean $(\ln ($ children +1$))$ & 0.133 & 2.314 \\
\hline Mean $(\ln ($ adults $))$ & 0.075 & 1.212 \\
\hline Std. dev. of indiv.random effect $\varepsilon_{n}$ & 0.766 & \\
\hline$\%$ variance due to $\varepsilon_{n}$ & 0.778 & \\
\hline Number of observations & 17,575 & \\
\hline Number of individuals & 7619 & \\
\hline \multicolumn{3}{|l|}{$R^{2}:$} \\
\hline Within & 0.003 & \\
\hline Between & 0.047 & \\
\hline Overall & 0.038 & \\
\hline
\end{tabular}

Note: There are dummies for missing variables, which are not included in the table. Although this method of dealing with missing variables is fairly standard, it should be noted that the method may bias some estimates. We refer to Jones (1996). A probably better method is 'pairwise deletion', but here we have still the difficulty that missing may be non-random but auto-selective.

Source: Table 3.12 in Van Praag and Ferrer-i-Carbonell (2008a,b).

frequently 10 or more explanatory variables, where most of them appear to be significantly different from zero.

The many results in the literature demonstrate that the same equation explains the data fairly well and that mostly at least the signs 
are the same. For instance, males are in most countries less satisfied with their job than females under ceteris paribus conditions. The effect of age is parabolic in all countries. Satisfaction declines with age when people are young, reaching a minimum at about somewhere between 20 and 45, depending on the country, and increasing after that age. This parabolic age effect seems to be an empirical law, not only for job satisfaction, but also for nearly all other domain satisfactions as well except for health satisfaction (see Van Praag and Ferrer-i-Carbonell, 2004, 2008a,b). We will meet it again. Blanchflower and Oswald (2007) discovered the same age effect for life satisfaction, while Plug and Van Praag (1995) found the age-effect for financial satisfaction.

We distinguish between household income and work income. The household income is seen as a source of maintenance of the family, while work income is the income of the individual respondent, generated by his job. The latter income is a symbol of how the respondent's work is appreciated by his/her employer. Hence, it is not strange that household income is non-significant when explaining job satisfaction. Singles are less satisfied than people living together. As expected, work income is an important determinant, as it expresses 'the value' of the individual in his working environment. However, we see from the interaction with age that the effect of working income diminishes with rising age. Males are more sensitive with respect to their work income than females. Self-employed are more satisfied with their job than employees. The number of working hours has a negative effect, while work in overtime has a positive effect on job satisfaction. This may be explained again by the fact that the worker feels that his work is so important that overtime is needed. On the other hand work at night is for understandable reasons negatively evaluated. Somewhat unexpectedly, the number of children increases job satisfaction. In this equation we added some 'mean terms'. This is the average over all the periods observed. We get a better understanding if we write

$$
\begin{array}{rl}
0.416 & * \ln (\text { workincome })+0.006 * \text { meanworkincome } \\
= & 0.416 *[\ln (\text { workincome })-\ln (\text { meanworkincome })] \\
& +0.422 * \text { meanworkincome }
\end{array}
$$

The first term is the log-difference between actual wage and average wage during the period. We see then that for the UK job satisfaction 
is strongly affected both by momentary changes in pay and by the long-period average wage.

As we already said, Table 4.1 is just one example of the many studies on job satisfaction. However, some general points can be inferred from this. Job satisfaction can be empirically measured and explained, while the results are meaningful. By looking at the results it becomes possible to estimate the separate effects of job conditions, which could not be separately isolated until now by other methods. As such these results are valuable for handling human resources in firms, in industries and the public sector, and finally for government policy.

However, satisfaction as such remains an esoteric matter. Fortunately, it is mostly possible to make a translation into money terms. Consider for instance the effect of various kinds of labor contracts in the UK. Pouliakas and Theodossiou (2010) estimate the effect of differences in labor contracts on job satisfaction by including dummy variables for the various contract types. From their Table 4.2 we see that if somebody in the U.K. switches from a fixed (temporary) contract to a permanent contract, his satisfaction according to their estimates would increase by 0.113 . We may assign a monetary value to the switch, by looking for the income reduction that would neutralize the increase in job satisfaction. If his satisfaction should not increase, this can be done by reducing his $\log$ (meanwage) by $\Delta \log$ (meanwage). Using the coefficient for $\log$ (meanwage) this would imply solving the equation $0.129 \Delta \log ($ meanwage $)=0.113$ for $\Delta \log ($ meanwage $)$, which would suggest that meanwage would have to be decreased by a factor $\exp (-0.113 / 0.129)=42 \%$. Clearly, this result has to be taken with a grain of salt. First, the calculation is based on statistical estimates which in themselves contain a considerable inaccuracy. Second the functional specification is nice and tractable, but does it really reflect the indifference surface in enough detail to draw such far-reaching conclusions? Nevertheless, it demonstrates that in principle the results may be useful to translate non-monetary labor conditions into terms of money.

\subsection{Financial Satisfaction}

A second domain of life is one's financial situation. Obviously, information on this is retrieved by putting the question: 'How satisfied are 
you with your financial situation?' There are, a bit surprisingly, not too many studies on this issue. It seems according to Delaney et al. (2008) that the estimates by Van Praag et al. (2003) were the first. However, in this tract we shall consider the work by Delaney et al. (2008), which provides a very interesting example of an investigation of financial satisfaction. Moreover, it gives the possibility to introduce the reference mechanism. We reproduce their result in Tables 4.2 and 4.3.

Delaney et al. (2008) consider an Irish panel data set which ran over the period 1994-2001. We quote: 'The Living in Ireland Survey forms the Irish component of the European Community Household Panel (ECHP): an EU-wide project, co-ordinated by Eurostat, to conduct harmonized longitudinal surveys dealing with the social situation, financial circumstances and living standards of European individuals and households. The first wave of the ECHP was conducted in 1994, and the same individuals and households were followed each year. The survey ran for eight waves, until 2001'.

In their study of financial satisfaction they incorporate several elements we did not consider up to now. We shall not dwell on the econometric aspects of their estimation procedure; they applied Ordered Probit, where they added a random fixed effect error structure in order to take into account the inter-temporal correlations between the individual response errors.

Their structural model is the following equation

$$
\begin{aligned}
f_{i t}^{*}= & \alpha+\gamma f_{i t-1}+\beta_{1} \ln y_{i t}+\beta_{2}\left(\ln y_{i t}-\ln y_{i t-1}\right)+\beta_{3} \ln y_{r i t} \\
& +\beta_{4} \ln y_{h t}+\beta_{5}\left(\ln y_{h t}-\ln y_{h t-1}\right)+\sum_{k}^{K} \delta_{k} x_{k i t}+u_{i}+e_{i t}
\end{aligned}
$$

The authors postulate that satisfaction at time $t$ depends on financial satisfaction in the previous period $(t-1)$, on present individual income $y_{i t}$, the change in individual income over the last period, household income and again the change in household income, and the average income in the reference group. Moreover, they add a number of control variables to be looked at in a moment, which are rather interesting per se. In Table 4.2 the effects are estimated. We are naturally inclined to look at the effect of income first. The distinction 
Table 4.2. A financial satisfaction equation, Ireland.

\begin{tabular}{lccc}
\hline & Specif. 1 & Specif. 2 & Specif. 3 \\
\hline Lag log financial satisfaction & $0.2916^{* * *}$ & $0.2929^{* * *}$ & $0.2927^{* * *}$ \\
Level of individual Income & 0.0061 & -0.0061 & -0.0010 \\
Change in individual income & & $0.0319^{* * *}$ & $0.0287^{* * *}$ \\
Individual reference income & & & $-0.0311^{* *}$ \\
Level of household income & $0.3541^{* * *}$ & $0.3830^{* * *}$ & $0.3828^{* * *}$ \\
Change in household income & & $-0.0605^{* * *}$ & $-0.0591^{* * *}$ \\
Time dummies & Yes & Yes & Yes \\
Controls & Yes & Yes & Yes \\
Intercept 1 & $1.3900^{* * *}$ & $1.5063^{* * *}$ & $1.3950^{* * *}$ \\
Intercept 2 & $2.1233^{* * *}$ & $2.2393^{* * *}$ & $2.1280^{* * *}$ \\
Intercept 3 & $2.9491^{* * *}$ & $3.0647^{* * *}$ & $2.9535^{* * *}$ \\
Intercept 4 & $3.9136^{* * *}$ & $4.0290^{* * *}$ & $3.9179^{* * *}$ \\
Intercept 5 & $4.8631^{* * *}$ & $4.9786^{* * *}$ & $4.8676^{* * *}$ \\
Log likelihood & $-51,155$ & $-51,138$ & $-51,135$ \\
$n$ & 34,354 & 34,354 & 34,354 \\
\hline
\end{tabular}

Note: ${ }^{* * *}$ significance at $1 \%,{ }^{* *}$ significance at $5 \%$, and ${ }^{*}$ significance at $10 \%$. Source: Delaney et al. (2006).

between individual and household income is made because most people live within a household and then it is mostly household income that matters, because the partners add the individual incomes together. So we surmise that household income is the index of material household welfare. Indeed we see that household income has a solid positive effect, while individual income has no effect at all. However, the change in individual income has a short-term effect, as it is identified by many people with the evaluation of the outside world. In that respect changes in individual income are well-perceived by the individual respondent. Household income changes have a small but significant negative sign. The explanation according to Delaney et al. is that the partner who is not causing the increase is a bit jealous of his or her partner who is more successful than himself or herself with respect to money. Then the authors introduce a variable named reference income, which is constructed as the average log-income in the reference group, defined as individuals in the same age and education bracket. ${ }^{1}$ We shall have to talk about this reference mechanism later on in more detail. The idea is that individuals compare with their reference group members and,

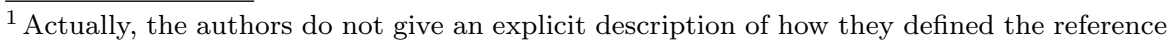
income concept.
} 
if the individual's reference group members are better-off on average, as a rule the individual himself feels more miserable. Indeed the sign of reference income is negative, but the size of the effect is not large. Finally, the authors expect that present financial satisfaction depends heavily on satisfaction a year before. Changes are translated with some temporal delay. We see that this effect is rather strong. Actually, we have here a first-order difference equation. What the authors estimate are short-term effects. If we rewrite the equation as

$$
f_{t}=\alpha+\gamma f_{t-1}+C
$$

where $C$ stands for all the other remaining terms, we get for the stationary equilibrium value $f$

$$
\begin{gathered}
f_{t}=\alpha+\gamma f_{t-1}+C \\
f=\frac{1}{1-\gamma}[\alpha+C]
\end{gathered}
$$

It follows that the long-term effect of household income on financial satisfaction is not 0.22 but about $0.22 /(1-0.44)=0.39$. It also follows for the coefficients $\delta$ of the other variables to be considered hereafter that their long-term counterparts are $\delta / 0.56=1.78 * \delta$

Now we consider the so-called controls in more detail. They are found in Table 4.3. It is seen that the number of adults in the household has a strong negative effect on financial satisfaction. No wonder,

Table 4.3. Control variables in the financial satisfaction equation, Ireland.

\begin{tabular}{lrlc}
\hline Log number of Adults & $-0.3352^{* * *}$ & Self-employed & 0.0327 \\
Log number of Children $(+1)$ & $-0.1689^{* * *}$ & Farmer & $-0.1844^{* * *}$ \\
Age & $0.0143^{* * *}$ & Relative assist & 0.0155 \\
Female & $-0.1145^{* * *}$ & Farm relative assist & $-0.3909^{* * *}$ \\
Married & $-0.1944^{* * *}$ & Training & 0.0224 \\
Female*married & $0.1512^{* * *}$ & Seek first job & $-0.6308^{* * *}$ \\
Junior certificate education & $0.1318^{* * *}$ & Unemployed & $-0.9046^{* * *}$ \\
Leaving certificate education & $0.1545^{* * *}$ & Unemployed ill & $-0.3940^{* * *}$ \\
Higher level education & $0.2338^{* * *}$ & Ill/disabled & $-0.3280^{* * *}$ \\
Poor health & $-0.1687^{* * *}$ & Retired & 0.0164 \\
Religiosity & $0.0362^{* * *}$ & Home duties & $-0.1127^{* * *}$ \\
Apprentice & -0.1437 & In education & $-0.3921^{* * *}$ \\
Temporary scheme & $-0.2802^{* * *}$ & & \\
\hline
\end{tabular}

Note: ${ }^{* * *}$ significance at $1 \%,{ }^{* *}$ significance at $5 \%$, and ${ }^{*}$ significance at $10 \%$. Source: Delaney et al. (2006). 
because there are more mouths to feed. Similarly the children effect is negative, but much less sizeable than that of adults. Actually, an increasing family size has to be countered by more household income to get the family equally satisfied financially. It is interesting to get an idea of what the trade-off is between family size and income. Let us assume that the number of adults in the household rises from 2 to 3 . It implies that $\Delta \log$ numberAdults $=\ln (3 / 2)=0.41$.

It follows from combining Tables 4.2 and 4.3 that household income has to be increased such that $-0.3352 * 0.41+0.38 *$ $\Delta \ln$ householdincome $=0$. It follows that log-household income has to be increased by

$$
\Delta \ln \text { householdincome }=\frac{0.3352 * 0.41}{0.38}=0.35
$$

in order to keep financial satisfaction constant. Hence, an increase by $50 \%$ of the number of adults is equivalent with an additional cost of about $\exp (0.35)=1.42-1=42 \%$. For infinitesimal changes we get an adult-equal financial satisfaction elasticity of $0.3352 / 0.38=0.88$. For children we find in a similar way a child-equal financial satisfaction elasticity of $0.1689 / 0.38=0.44$.

Of course, these results are important for formulating a family allowance policy. We come back to it later in Section 13. The effect of age seems to be satisfaction increasing. We notice that age is specified in years. Hence the seemingly small effect of 0.0143 is not that small at all. In most applications (e.g., see Van Praag and Ferrer-i-Carbonell, 2004, 2008a; Plug and Van Praag, 1995), it is found that the relation between financial satisfaction and age is also (log-) parabolic with a minimum at about 40. Indeed adults with a growing family and growing aspirations will consider the same amount of money as becoming less worth when growing older, until about 40. After that age they will grow more easily satisfied. This established fact might be important for re-evaluating the effect of demotion of older people and/or reducing the replacement ratios between pensions and salaries. We see that education makes people more satisfied, which may be caused by the fact that educated people are dealing with their money more efficiently. Poor health makes individuals less satisfied with their money and there is an even stronger negative effect of being unemployed. Notice that this 
is not caused by the fact per se that unemployed have a lower income, for income itself is already included as a variable. Farmers are much less satisfied and the same holds to a lesser extent for individuals with 'home duties'.

\subsection{Health Satisfaction}

Another application of the satisfaction approach is dealing with health. We notice that the question is: How dissatisfied or satisfied are you with your health? This question has been posed in the British Household Panel Survey (BHPS) since 1996. We call the answer to this question the individual's Health Satisfaction $(H)$. In the BHPS individuals are asked to restrict their answers from 1 to 7 , where 1 stands for 'very dissatisfied' and 7 for 'very satisfied'. It is obvious that this question is a crucial one for health economics, health being one of the primary issues in Western societies. With about $10 \%$ of the national product being consumed in terms of health care, health is one of the basic products in Western society. However, how do we measure the output of health care? What are the determinants of health? Is it possible to assign a money value to health improvements? For the establishing of health policy and the evaluation of policy instruments it is of course crucial to be able to assess the impact of that policy.

The evaluation is mostly in terms of national life expectations or some other general measure. In health economics the questions are frequently more pointed. What determines individual health and how can we improve individual health?

Health may be evaluated by medical doctors, nurses, etc. and then it is mostly done in terms of physical and mental capabilities of the individual. A rather different approach is to take the feelings of the individuals themselves as starting point of the analysis. Then we have to base ourselves on questions like the satisfaction question described above and/or more elaborate subjective question modules like the SF-36, which was first made available in a "developmental" form in 1988 and in "standard" form in 1990 (Stewart et al., 1988; Ware and Sherboune, 1992). They decompose health into components like physical health and mental health, where each of the eight components is measured on a 
six-scale. For instance, "physical functioning" ranges from 'Very limited in performing all physical activities, including bathing or dressing' to 'Performs all types of physical activities including the most vigorous without limitations due to health'. Here the responses are given by the respondents themselves. This raises two problems. The first is that different individuals will have different norms. That is, what is a rather modest health situation for a 30 -year-old person will be probably seen as excellent health for an 80-year-old person. Without taking these background circumstances into account, the individual answers are not well-comparable. The second point is the structure of the battery as a multitude of questions. It poses the problem of how to summarize the outcomes on the components.

The approach by posing just one question asking for one's satisfaction with health is more fitting in general surveys, and it gives less interpretation problems for respondents than a whole battery of questions. It has been shown that the answers to such simple health satisfaction questions predict future mortality (e.g., Frijters et al., 2011b).

As an example of the approach we present estimation results that are borrowed from our treatise Happiness Quantified (Section 9, Table 9.1). We estimated a health satisfaction equation on a UK sample (BHPS) where we included specific health-related determinants, i.e., ailments and illnesses, and some general determinants like age, education, etc.

Looking at the general determinants of health we see that the age of the individual, here operationalized as $\ln (a g e)$, is rather important for health perception. Under ceteris paribus conditions the picture of health as function of age looks like a parabolic curve with a minimum at the age of 32 . This behavior shows that perception of health differs fundamentally from the objective health status. There can be no confusion about the fact that health, measured by means of objective measures, deteriorates monotonically, when age increases. Nevertheless, the subjective perception is that individuals become more satisfied with their existing health, when they grow older. Perception is agedependent. Clearly, there are many age-related illnesses, and when they appear with increasing age they have a specific worsening effect on health satisfaction. It is also seen that more education does not help. 
Table 4.4. Health satisfaction, workers, UK, 1996-1998, POLS individual random effects.

\begin{tabular}{|c|c|c|}
\hline & Estimate & $t$-Ratio \\
\hline Constant & 2.927 & 2.978 \\
\hline Dummy for 1996 & -0.083 & -5.388 \\
\hline Dummy for 1997 & -0.019 & -1.323 \\
\hline Ln(age) & -1.307 & -2.323 \\
\hline$(\operatorname{Ln}(\text { age }))^{2}$ & 0.189 & 2.368 \\
\hline Minimum age & 32 & \\
\hline Ln(family income) & -0.040 & -1.766 \\
\hline $\operatorname{Ln}($ years education $)$ & -0.096 & -3.825 \\
\hline Ln $($ children +1$)$ & -0.023 & -0.443 \\
\hline Gender (male) & 0.008 & 0.386 \\
\hline Living together & -0.003 & -0.118 \\
\hline Self-employed & 0.056 & 1.857 \\
\hline $\operatorname{Ln}($ savings) & 0.011 & 2.213 \\
\hline Problems with arms, legs, hands, feet, back, or neck & -0.409 & -18.921 \\
\hline Difficulty in seeing & -0.169 & -3.269 \\
\hline Difficulty in hearing & -0.153 & -3.534 \\
\hline Skin conditions/allergies & -0.172 & -6.647 \\
\hline Chest/breathing problems & -0.398 & -13.544 \\
\hline Heart/blood problems & -0.436 & -12.204 \\
\hline Problems with stomach/liver/kidneys & -0.493 & -13.141 \\
\hline Diabetes & -0.562 & -6.232 \\
\hline Epilepsy & -0.517 & -3.818 \\
\hline Migraine or frequent headaches & -0.249 & -8.397 \\
\hline Other health problems & -0.603 & -14.515 \\
\hline Mean $(\ln ($ family income $))$ & -0.011 & -0.369 \\
\hline Mean $(\ln ($ children +1$))$ & 0.073 & 1.297 \\
\hline Mean $(\ln ($ adults $))$ & 0.009 & 1.320 \\
\hline \multicolumn{3}{|l|}{ Std. dev. of indiv.random effect $\varepsilon_{n}$} \\
\hline Individual & 0.734 & \\
\hline Error standard deviation & 0.772 & \\
\hline$\%$ Variance due to $\varepsilon_{n}$ & 0.474 & \\
\hline Number of observations & 17,966 & \\
\hline Number of individuals & 7780 & \\
\hline \multicolumn{3}{|l|}{$R^{2}:$} \\
\hline Within & 0.021 & \\
\hline Between & 0.169 & \\
\hline Overall & 0.128 & \\
\hline
\end{tabular}

Note: There are dummies for non-missing variables, which are not included in the table.

Source: Van Praag and Ferrer-i-Carbonell (2004, 2008b).

Higher-educated people are less satisfied with their health under ceteris paribus conditions than individuals with less education. Not surprisingly, the occurrence of medical problems has a strong effect on health perception. All these effects appear to be very significant. We also see 
that income, gender, and family composition have no significant effects on the perception of health.

Is it now also possible to attach a monetary value on the health loss, caused by having, e.g., migraine, just as we assigned a monetary value to the switch from one type of labor contract to another in the framework of job satisfaction. However, here we see that this trick is blocked because the income effect on health satisfaction is very small and non-significant. Hence, we would have to divide by a number near zero, yielding a very high and uncertain monetary loss due to migraine. We will come back to this issue later on.

What we can do, however, is to utilize the health satisfaction question for a new and intuitively plausible definition of subjective health and for a definition of subjective health losses due to illnesses. After all, the satisfaction scale may be interpreted as a cardinal scale. We identify the response 1 on a $1-7$-scale with the worst health conceivable and 7 with excellent health conceivable, which on a percentage scale may be re-scaled to $0 \%$ and $100 \%$ respectively. Then category 4 translates into $(4 / 7)^{*} 100=57 \%$ and so on. Then we may evaluate health differences between situations $\mathrm{A}$ and $\mathrm{B}$ by $H(A)-H(B)$ and relative differences by $(H(A)-H(B)) / H(A)$. In Van Praag and Ferrer-i-Carbonell, (2001) we made such calculations based on the health satisfaction equation and we found the results in Table 4.5. In Table 4.5 we present the absolute and relative health losses caused by various diseases, where we differentiate for two ages, viz. 30 and 60 .

We see that difficulties in seeing and hearing are not perceived as serious health losses, while chest-breathing problems, diabetes, and depressions cause more serious losses. Aggregating this kind of numbers over the total population gives an index for average subjective health and an idea of the efficacy of various health-improving policies. Therefore the first column in Table 4.5 presents the average health level of healthy individuals of age 30 and 60 respectively. The value of the losses has to be set into perspective by comparing them with the health evaluation of people, not afflicted by the mentioned illnesses. The baseline appears to be about 0.840 for 30 years old and 0.862 for 60 years old. These values provide numerical losses that might be taken as an alternative to the QALY (Quality Adjusted Life Years)-approach. 
Table 4.5. Health losses caused by various diseases.

\begin{tabular}{|c|c|c|c|c|}
\hline & \multicolumn{2}{|c|}{$\begin{array}{l}\text { Absolute health } \\
\text { loss }\end{array}$} & \multicolumn{2}{|c|}{$\begin{array}{c}\text { Relative health } \\
\text { loss }\end{array}$} \\
\hline & 30 & 60 & 30 & 60 \\
\hline Average health for individuals without diseases & 0.840 & 0.862 & - & - \\
\hline Problems with arms, legs, hands, feet, back, or neck & 0.147 & 0.137 & 0.175 & 0.159 \\
\hline Difficulty in seeing & 0.061 & 0.056 & 0.073 & 0.065 \\
\hline Difficulty in hearing & 0.019 & 0.017 & 0.023 & 0.020 \\
\hline Skin conditions/allergies & 0.025 & 0.023 & 0.030 & 0.027 \\
\hline Chest/breathing problems & 0.100 & 0.114 & 0.119 & 0.132 \\
\hline Heart/blood problems & 0.161 & 0.089 & 0.192 & 0.103 \\
\hline Stomach/liver/kidneys & 0.219 & 0.111 & 0.261 & 0.129 \\
\hline Diabetes & 0.176 & 0.096 & 0.210 & 0.111 \\
\hline Anxiety, depression, or bad nerves & 0.203 & 0.190 & 0.242 & 0.220 \\
\hline Alcohol or drug-related problems & 0.262 & 0.247 & 0.312 & 0.287 \\
\hline Epilepsy & 0.170 & 0.158 & 0.202 & 0.183 \\
\hline Migraine or frequent headaches & 0.037 & 0.033 & 0.044 & 0.038 \\
\hline Other health problems & 0.234 & 0.158 & 0.279 & 0.183 \\
\hline
\end{tabular}

Source: Van Praag and Ferrer-i-Carbonell (2008b).

We have looked now after the effect of some illnesses on the subjectively perceived health condition. However, is this the only life domain that can be affected by health problems? The answer is no.

Now we consider some other life domains, where we simultaneously include health variables. The first one is again job satisfaction. We estimated job satisfaction again, but now we added a number of health variables, which we used also in the health satisfaction equation. The estimates in Table 4.1 can be compared with those in Table 4.6. Due to the fact that we added the health variables and also left out a few of the variables included in the earlier specification, we arrive at different estimates. However, the differences between with respect to the effects of the variables common to Tables 4.1 and 4.6 are mostly not dramatic. We have to stay aware of the effect that there is no true specification. Any specification is an approximation of the empirical relationship, which can never be described exactly by a neat mathematical formula.

What is the interesting new feature of the results in Table 4.6? It is the effects of the different illnesses on job satisfaction, which are rather formidable indeed. All these effects are negative and highly significant. 
Table 4.6. Job sat. with health effects included, UK, 1996-1998, POLS indiv. random effects.

\begin{tabular}{lrr}
\hline & Estimate & $t$-Ratio \\
\hline Constant & 11.362 & 9.865 \\
Dummy for 1996 & -0.019 & -1.214 \\
Dummy for 1997 & 0.009 & 0.648 \\
Ln(household income) & 0.055 & 1.853 \\
Ln(age) & -7.158 & -10.700 \\
Ln (age) & 1.052 & 11.139 \\
Living together & 0.167 & 4.514 \\
Gender (male) & -0.121 & -4.434 \\
Ln(years education) & -0.084 & -3.278 \\
Ln(work income) & 0.014 & 1.104 \\
Ln(working hours) & 0.007 & 0.348 \\
Ln(extra hours) & 0.042 & 3.876 \\
Self-employed & 0.163 & 2.293 \\
Ln(desired hours) & 0.218 & 11.093 \\
Work at night & -0.125 & -2.092 \\
Second earner in the household & -0.042 & -1.395 \\
Ln(Hours household work) & -0.027 & -1.788 \\
Ln(children +1) & 0.249 & 1.010 \\
(Ln children +1) & & \\
Ln(adults) & 0.053 & 0.944 \\
Ln[(children +1)*income] & -0.113 & -2.235 \\
Ln(children +1)*living together & -0.043 & -1.422 \\
Problems with arms, legs, hands, feet, back, or neck & 0.027 & 0.523 \\
Difficulty in seeing & -0.130 & -5.918 \\
Difficulty in hearing & -0.073 & -1.390 \\
Skin conditions/allergies & -0.032 & -0.732 \\
Chest/breathing problems & -0.025 & -0.934 \\
Heart/blood problems & -0.049 & -1.647 \\
Problems with stomach/liver/kidneys & -0.040 & -1.098 \\
Diabetes & -0.102 & -2.677 \\
Depression & 0.070 & 0.752 \\
Alcohol or drug-related problems & -0.341 & -9.152 \\
Epilepsy & -0.122 & -0.673 \\
Migraine or frequent headaches & 0.114 & 0.840 \\
Other health problems & -0.060 & -2.006 \\
Mean (ln(household income)) & -0.047 & -1.126 \\
Mean (ln(children +1)) & -0.031 & -0.849 \\
Mean (ln(adults)) & 0.100 & 1.736 \\
Mean (ln(work income)) & 0.057 & 0.932 \\
Mean (working hours) & 0.000 & -0.031 \\
Mean (overtime) & 0.004 & 0.170 \\
Mean (desired hours) & 0.011 & 0.629 \\
Mean (household work) & 0.208 & 6.289 \\
\hline & & 2.128 \\
\hline
\end{tabular}


Table 4.6. (Continued)

\begin{tabular}{lcc}
\hline & Estimate & $t$-Ratio \\
\hline Std. dev. of indiv.random effect $\varepsilon_{n}$ & 0.743 & - \\
Error Standard deviation & 0.772 & - \\
\% Variance due to $\varepsilon_{n}$ & 0.481 & - \\
Number of observations & 17,563 & - \\
Number of individuals & 7617 & - \\
R2: & 0.019 & - \\
Within & 0.089 & - \\
Between & 0.074 & \\
Overall &
\end{tabular}

It follows that when we limit the effect of health limitations to their effect on health satisfaction only, we do not get a correct idea of the impact of health on other life domains.

Similar effects are found for other life domains like financial satisfaction, leisure satisfaction and satisfaction with social life. We refer for a detailed account to Van Praag and Ferrer-i-Carbonell (2004, 2008a). For an interesting account of housing satisfactions we refer to De Lora et al. (2010). In that volume we find many papers on satisfaction with housing (in Latin-America) where the determinants are not only characteristics of the individual and of the house but also of the urban environment, like the crime rate, distance to education facilities, availability of public traffic, the slope of the road, etc., yielding most fascinating effects. 


\section{Cardinal or Ordinal?}

In the previous sections the concept of happiness is taken as being ordinal. This was the case when using OLS, Ordered Probit and POLS. Ordinality means that evaluation of happiness in numerical terms like ' 7 ' on a $0-10$-scale has no interpretation other than that the respondent feels happier than somebody answering ' 6 ' and less happy than somebody who answers ' 8 ' to the same question. Now it may be prudent to position oneself at the agnostic side when responses are cast in verbal terms like 'bad', 'sufficient', 'good' or 'excellent'. However, when it comes to numerical evaluation, it may be seen as a too prudent approach, for the respondents themselves most probably interpret the evaluations in cardinal terms. At least, this is true when individuals evaluate school grades, consumer goods, services, etc. on a numerical scale. Then a jump from A to B is thought to be equal to a jump from B to C. Similarly the change from an evaluation ' 8 ' to ' 7 ', seems to be the same as from ' 7 ' to ' 6 ' (cf. Parducci, 1995; Van Praag, 1991). Then it seems improbable that respondents would do differently when evaluating their degree of satisfaction with life. Actually, it may be defended that the methods OLS, Ordered Probit and POLS are implicitly based on a cardinal concept as well. These methods are all based on some 
kinds of distance (or squared residual) minimization and those residuals themselves imply a cardinalization.

A somewhat older way of asking satisfaction questions has been invented by Cantril (1965). He supplied the respondent with a ladder with 10 equidistant rungs, where the top rung stood for the excellent life and the lowest rung for the worst life possible. The respondent is asked to position himself on the rung that corresponds the best with his satisfaction with life. The answers to such a ladder question are also given on the implicit assumption that the distances between rungs stand for equal satisfaction differences.

If we accept this cardinal interpretation, then we may describe the relation between life satisfaction $U_{n}$ of respondent $n$ and personal characteristics $x_{n}$ by a function between 0 and 1 , say, $F\left(x_{n} ; \beta\right)$. If the indifference surfaces are linear hyper-planes it may be written as $F\left(\beta^{\prime} x_{n}\right)$. Then the specification $U_{n}=N\left(\beta^{\prime} x_{n} ; 0,1\right)$ lies at hand, where $N(\cdot ; 0,1)$ stands for the standard- normal distribution function. ${ }^{1}$ Now we define the values $u=N^{-1}(U)$. In the case of discrete response classes for a respondent answering 7, we may assume that his true value $U$ that we cannot exactly observe will lie between 6.5 and 7.5. It follows that his true value $u$ will lie between the normal quantiles $u_{0.65}$ and $u_{0.75}$. Then two values lie at hand. The first is found by assigning to the respondent the conditional average

$$
u_{i}=E\left(u \mid u_{o .65}<u \leq u_{0.75}\right)=\frac{n\left(u_{0.65}\right)-n\left(u_{0.75}\right)}{N\left(u_{0.75}\right)-N\left(u_{0.65}\right)}
$$

The second potential candidate is the median value on that interval, defined by

$$
u_{7}^{(m)}=N^{-1}(0.7)
$$

For the extremes we have to make a slight modification. The left extreme 0 is assigned to the interval $[0,0.05]$ and the right extreme 10 to $[0.95,1.0]$. The resulting values $u_{i_{n}}$ are regressed on the vector $x_{n}$. These methods have been called the Cardinal OLS-method (COLS) and the Cardinal Median- method (CM), respectively in Van Praag

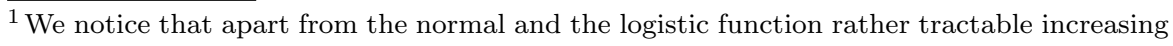
functions between 0 and 1 with as range the real axis are not easily found. 
and Ferrer-i-Carbonell (2008b, Section 2). There it has been shown that trade-off estimates are not significantly different from those estimated by POLS, while the estimates' reliabilities, measured by $t$-values, is of about the same order as well. The advantage of the two latter methods is that we can employ the cardinal character of the responses, as we will do later on. 


\section{6}

\section{Aggregating Domain Satisfactions to Life Satisfaction}

We have now seen that both domain satisfactions and life satisfaction can be empirically defined and measured and that their explanation makes intuitive sense. The question is now: what is the link between domain satisfactions and life satisfaction? Let us denote life satisfaction, in accordance with earlier literature, by General Satisfaction $(G S)$ and domain satisfactions with domains $i=1, \ldots, I$ by $D S_{1}, \ldots, D S_{I}$ respectively, then we may assume a relation

$$
G S=G S\left(D S_{1}, \ldots, D S_{I}\right)
$$

which states that $G S$ can be seen as an aggregate of the different domain satisfactions. It may be expected that the function is increasing in all its arguments, that is, if satisfaction with one of the domains increases, while the other $D S$ ' s remain constant, then $G S$ increases as well. The specification

$$
G S=\alpha_{1} D S_{1}+\cdots+\alpha_{I} D S_{I}+\alpha_{0}+\varepsilon
$$

lies then at hand. This is indeed the specification that has been first introduced by Van Praag et al. (2003) and Ferrer-i-Carbonell and Van Praag (2002). See also Easterlin and Sawangfa (2009) and Kapteyn et al. (2010). 
The first practical question is the cardinalization to be used. Extending the POLS-cardinalization of $G S_{n}$ we take for each $D S_{i, n}$ the POLS-value of the response by respondent $n$ at domain question $i$. The other cardinalizations suggested in Van Praag and Ferrer-i-Carbonell $(2004,2008 b)$ give the same qualitative results. However, there is a second complicating factor. That is that there may be correlation between the $D S_{i, n}$ 's and the error term $\varepsilon_{n}$. In that case one of the basic requirements of OLS-analysis would be violated. This may be the case, e.g., if an individual is rather optimistic and evaluates everything at the bright side of life. He evaluates his domains higher than normally expected and he evaluates his general life situation better than normally expected as well. The same holds for born pessimists. In that case the disturbances $\varepsilon_{i}, \varepsilon_{G S}$ would be correlated. Indeed it is found (see Van Praag and Ferrer-i-Carbonell, 2004, 2008b, Section 4) that the error terms of different domain equations are significantly positively correlated. Using the principal component decomposition of the domain error covariance matrix in order to define for each respondent his first principal component contribution $Z_{n}$, we estimated the equation

$$
G S_{n}=\alpha_{1} D S_{1 n}+\cdots+\alpha_{I} D S_{I n}+\alpha_{0}+\alpha_{Z} Z_{n}+\varepsilon_{n}
$$

where $Z_{n}$ stands for the common first principal component of the domain errors. The term $\varepsilon_{n}$ is then the residual after filtering for the common component $Z_{n}$.

A typical example of such an estimated equation is presented in Table 6.1.

Table 6.1. Level effects for the British data set.

\begin{tabular}{lcc}
\hline & Workers & Non-workers \\
\hline Job satisfaction & 0.112 & - \\
Financial satisfaction & 0.064 & 0.087 \\
Housing satisfaction & 0.041 & 0.057 \\
Health satisfaction & 0.102 & 0.166 \\
Leisure-use satisfaction & 0.109 & 0.237 \\
Leisure-amount satisfaction & 0.036 & -0.025 \\
Marriage satisfaction & 0.071 & 0.068 \\
Social-life satisfaction & 0.116 & 0.187 \\
\hline
\end{tabular}

Note: Constant intercept and $Z$-effect are not presented here. Source: Van Praag and Ferrer-i-Carbonell (2008b). 
We see here life satisfaction decomposed as an aggregate of eight life domains, each with its own effect on life satisfaction. Roughly speaking for working people job satisfaction and social-life satisfaction are equally important, very closely followed by health satisfaction and leisure-use satisfaction. The last stands for the evaluation of how we spend our leisure time. In a second tier we find the other four life domains considered. It is notable that satisfaction with the own marriage scores much lower than the satisfaction with social life. Contrary to the intuition of still many economists financial satisfaction is not the fundamental determinant of life satisfaction. For non-workers, e.g., students, retired, non-working housewives and for unemployed whose job satisfaction is undefined, the effects are even more pronounced. It is also interesting that having (too) much leisure time may have a negative effect for non-workers.

A similar approach may be applied, using different cardinalizations, see, e.g., Kapteyn et al. (2010).

We notice that the domain satisfactions are determined by observable factors $x$. For instance, if age has a strong effect on job satisfaction (as we saw from Table 4.1 on job satisfaction) it implies that age has an effect via job satisfaction on satisfaction with life as a whole. But age has also an effect via health satisfaction and via most other domains. Hence, we see that the same variable $x$, e.g., age, may affect life satisfaction via different channels simultaneously. These partial effects are of course not observed when we put in the variable age directly as explanatory variable for life satisfaction. It may even be that the effect of a variable $x$ on one domain is positive and negative in another, such that the aggregate effect on life satisfaction is zero. For instance, age has a negative effect on health satisfaction, while its effect on financial satisfaction is positive after about 40 years of age. Actually, this is a two-layer model. It is described by the arrow model in Figure 6.1.

The obvious advantages of this split-up are that domains are easier and better to explain than life as a whole and that it becomes possible to disentangle the overall effect of a variable. We may identify through which domain channels the effects are transferred to satisfaction with life as a whole. On the other hand if such domains are too narrowly 


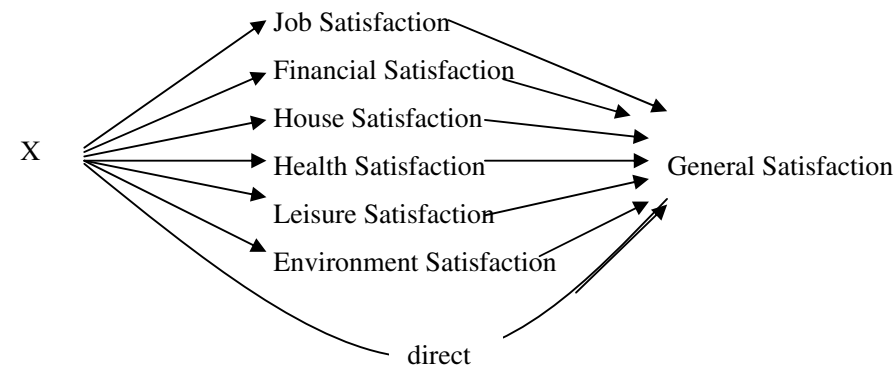

Fig. 6.1 The link between domain satisfactions and general satisfaction.

defined, e.g., satisfaction with sport, music, smoking, etc. instead of leisure satisfaction, we run the danger that explanatory variables are difficult to find, that their effects are difficult to identify, and the number of domains is getting too large in order to explain overall satisfaction meaningfully. Or more plainly speaking, how to specify the model exactly is an art, and the success can only be measured by looking at the intuitive plausibility of the estimated outcomes.

A similar approach may be applied on domain satisfactions themselves. Take, for instance, job satisfaction. In Van Praag and Ferrer-iCarbonell (Section 4) one may find an example on data from the British Household Panel. The questionnaire contains a question with respect to 'job satisfaction as a whole', but alongside there are satisfaction questions posed with respect to several aspects of the job. ${ }^{1}$ Again there are 7 satisfaction levels specified. The aspects are: promotion prospects, total pay, relations with supervisor, job security, opportunity to take initiative, satisfaction with the work itself and with the number of hours worked. We now re-estimate the regression for JS, where we specify the equation as an aggregate of those sub-domain satisfactions as follows:

$$
\begin{aligned}
J S= & \alpha_{1} J S P R O M+\alpha_{2} J S P A Y+\alpha_{3} J S B O S S+\alpha_{4} J S S E C U R \\
& +\alpha_{5} J S I N I T+\alpha_{6} J S W O R K+\alpha_{7} J S H O U R S+\beta . Z_{J S \cdots}
\end{aligned}
$$

The estimation results are presented in Table 6.2.

\footnotetext{
${ }^{1}$ Some of the sub-domain job-satisfaction questions were not posed after 1997.
} 
Table 6.2. Level effects of various job aspects on job satisfaction.

\begin{tabular}{lr}
\hline Satisfaction with promotion & 0.148 \\
Satisfaction with pay & 0.179 \\
Satisfaction with supervisor & 0.171 \\
Satisfaction with job security & 0.118 \\
Satisfaction with initiative & 0.046 \\
Satisfaction with work itself & 0.276 \\
Satisfaction with hours worked & 0.143 \\
\hline Source: Van Praag and Ferrer-i-Carbonell \\
(2008a, Table 6.3).
\end{tabular}

The sub-domain satisfactions themselves may be explained by objectively measurable variables. Actually, we have here a three-layer model. Hence, it becomes possible to dissect well-being into domains of well being that on their turn can be separately analyzed. It is evident that this model may be extended to multi-layer models. 


\section{Leyden School}

It is frequently thought that happiness economics started in the nineties of the previous century with the lonesome precursor Easterlin (1974). However, in the seventies there was already much similar activity avant la lettre, which later on became known as the Leyden School, named after the Dutch university where this line of research was started. It seems appropriate at this point to make a digression on the Leyden School, not only for historical reasons but because this work is still relevant for present day happiness economics.

The beginning is now mostly identified with Van Praag (1971a). In that paper Van Praag built on his earlier monograph (1968) where he argued that a utility function of income $U(y)$ where $y$ stands for income, called by him then the Individual Welfare Function of Income (WFI), can be seen as a cardinal concept and that it is likely to be approximately a lognormal distribution function. In Van Praag (1971a) the first attempt was made to estimate such a utility function on the basis of survey data, where a kind of subjective satisfaction question was posed. This was the so-called Income Evaluation Question (IEQ). We quote a German version. 
Whether you feel an income is good or not so good depends on your personal circumstances and expectations.

In your case would you call your net household income:

a very low income if it equaled

a low income if it equaled

an insufficient income if it equaled

a sufficient income if it equaled

a good income if it equaled

a very good income if it equaled
$\mathrm{DM}$

$\mathrm{DM}$

$\mathrm{DM}$

$\mathrm{DM}$

$\mathrm{DM}$

$\mathrm{DM}$ (per month) (per month) (per month) (per month) (per month) (per month)

There are several wordings of this question. First, the number of levels has varied over time between 4 and 9 . When it was first posed in a Belgian survey (Van Praag, 1971a), 9 verbally described levels were used. In Russian surveys (see Ferrer-i-Carbonell and van Praag, 2001) 5 levels have been used. Second, in the earliest versions (1971) the question was formulated in a bit more complex way. In order to estimate a utility function a log-normal relationship like sketched in Figure 7.1a and $\mathrm{b}$ was assumed. The crucial point is the assumption we are willing to make about the response behavior. Let the income levels in the question above be denoted by $c_{1}, \ldots, c_{6}$, then Van Praag assumed
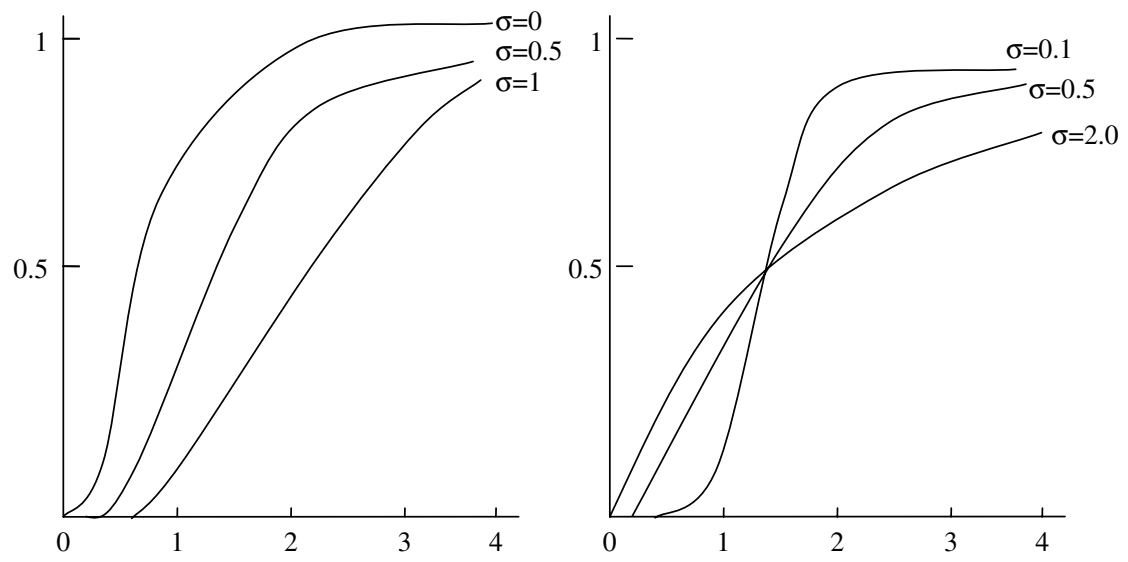

Fig. 7.1 The Lognormal distribution functions for different parameter values. (a) Distribution functions for $\mu=0,0.5,1$. (b) Distribution functions for $\sigma=0.1,0.5$. 
that the respondent attempts to answer in such a way that $U\left(c_{1}\right)=$ $1 / 12, \ldots, U\left(c_{6}\right)=11 / 12$. In words, the corresponding utility steps are the midpoints of the intervals $[0,1 / 6],(1 / 6,2 / 6], \ldots,(5 / 6,1]$, analogous to the equal distance assumption implicit in Cantril's ladder question. Generalization to more or less levels is obvious. This was called the 'equal jump'-assumption. The lognormal assumption boils then down to the hypothesis that

$$
U\left(c_{1}\right)=N\left(\ln c_{1} ; \mu, \sigma\right)=1 / 12, \ldots, U\left(c_{6}\right)=N\left(\ln c_{6} ; \mu, \sigma\right)=11 / 12
$$

or

$$
\ln \left(c_{i}\right) \approx u_{(2 i-1 / 12)} \cdot \sigma+\mu \quad i=1, \ldots, 6
$$

where $u_{\alpha}$ stands for the $\alpha$-quantile of the standard normal distribution. Having six (or in the original paper even nine) responses per individual $n$ it is possible to estimate two individual parameters $\mu_{n}, \sigma_{n}$, for instance by OLS. Obviously the estimates of the WFI's parameters are not very exact as they are derived from six observations per individual respondent, and the number of observations cannot be increased very much, since we would have to ask respondents for an ever finer differentiation. The basic 'equal jump' assumption was tested in Van Praag (1991) by asking individuals which figure between 0 and 10 they associated with the verbal levels in the IEQ. The result was that the assumption could not be rejected.

The resulting parameters $\mu_{n}$ and $\sigma_{n}$ appeared to differ between individuals, giving proof of the fact that individuals have different utility functions of money. The parameter $\sigma_{n}$ could not be explained very well by individual characteristics, but $\mu_{n}$ could be explained very well. In Figure 7.1a and b we sketch the function for different values of $\mu$ and $\sigma$. We see that $U\left(e^{\mu}\right)=0.5$ and that this median point on the income axis shifts to the right with increasing $\mu$. The parameter $\sigma$ is a slope parameter, where an increase in $\sigma$ makes the curve flatter. The parameter $\sigma$ is called the welfare sensitivity.

Now we try to find the relationship between the personal parameter $\mu_{n}$ and personal characteristics $x_{n}$ of the individual $n$. That is, we estimate an equation $\mu_{n}=f\left(x_{n}\right)$. The proto-typical equation for 
explaining $\mu$ is

$$
\mu_{n}=\beta_{0}+\beta_{1} \ln \left(f s_{n}\right)+\beta_{2} \ln \left(y_{n}\right)+\varepsilon_{n}
$$

where $f s$ stands for family size and $y$ for household income. The first reliable estimate of such an equation is found in Van Praag and Kapteyn (1973) on a Dutch sample of more than 3000 respondents. A typical estimate of this equation, which is estimated for many countries since then, is

$$
\mu_{n}=\beta_{0}+0.1 \ln \left(f s_{n}\right)+0.6 \ln \left(y_{n}\right)+\varepsilon_{n}
$$

It follows that the evaluation of an income level $y$ by individual $n$ is calculated to be

$$
N\left(\ln (y) ; \mu_{n}, \sigma_{n}\right)=N\left(\frac{\ln (y)-\beta_{0}-\beta_{1} \ln \left(f s_{n}\right)-\beta_{2} \ln \left(y_{n}\right)}{\sigma_{n}} ; 0,1\right)
$$

The observation that utility functions differ between individuals was rather new in 1971. Especially the fact that utility functions depended on the individual's own income, although intuitively very plausible, was never made before and empirically estimated. It is now easy to find the evaluation of the respondent's own income. It equals

$$
N\left(\ln \left(y_{n}\right) ; \mu_{n}, \sigma_{n}\right)=N\left(\frac{\ln \left(y_{n}\right)-\beta_{0}-\beta_{1} \ln \left(f s_{n}\right)-\beta_{2} \ln \left(y_{n}\right)}{\sigma_{n}} ; 0,1\right)
$$

This was called the true income evaluation function. The most interesting parameter is $\beta_{2}$, which was called in the 1971 paper the preference drift parameter. If $\beta_{2}=0$ the dependency on own income is nil, but if $\beta_{2}=1$ the evaluation of own income is $N\left(\frac{-\beta_{0}-\beta_{1} \ln \left(f s_{n}\right)}{\sigma_{n}} ; 0,1\right)$. That is, if $\beta_{2}=1$ the evaluation of own income is constant, irrespective of the level of own income. This reminds very much on modern 'set-point'theory. It is obvious that the larger $\beta_{2}$, the smaller the influence of an income increase.

It is now tempting to lay the link between the Leyden concepts and modern happiness economics. In modern happiness questions the respondent $n$ is asked to assign an evaluation $U_{n}$ between 0 and 10 (or between 1 and 7 , etc.) to his life as a whole or for domains like financial satisfaction. We estimate the financial satisfaction function 
by the COLS-or CM-method. We notice that also here income $y_{n}$ is evaluated by a lognormal distribution function, if we keep all other variables constant.

Now the hypothesis is that the true WFI in Leyden terminology equals the financial satisfaction evaluation in modern terminology. If that holds then there should hold

$$
\begin{aligned}
N^{-1}\left(U_{j_{n}}\right) & \approx \frac{\ln \left(y_{n}\right)-\beta_{0}-\beta_{1} \ln \left(f s_{n}\right)-\beta_{2} \ln \left(y_{n}\right)}{\sigma_{n}} \\
& \approx \alpha_{1} \ln \left(f s_{n}\right)+\alpha_{2} \ln \left(y_{n}\right)+\alpha_{0}
\end{aligned}
$$

where $\alpha_{1}=-\beta_{1} / \sigma_{n}, \alpha_{2}=\left(1-\beta_{2}\right) / \sigma_{n}$, and $\alpha_{0}=-\beta_{0} / \sigma_{n}$. We take here the more or less random parameter $\sigma_{n}$ equal to its average over the sample.

As is shown in Van Praag and Ferrer-i-Carbonell (2004, 2008a,b) this equality is found indeed.

Summarizing we have at least five methods to estimate from the financial satisfaction question the corresponding financial satisfaction equations. First, we have the four methods already considered that yield

$$
\begin{gathered}
u_{n}^{(O P)}=\beta_{0}^{(O P)}+\beta_{1}^{(O P)} x_{1 n}+\cdots+\beta_{m}^{(O P)} x_{m n} \\
u_{n}^{(P O L S)}=\beta_{0}^{(P O L S)}+\beta_{1}^{(P O L S)} x_{1 n}+\cdots+\beta_{m}^{(P O L S)} x_{m n} \\
u_{n}^{(C O L S)}=\beta_{0}^{(P O L S)}+\beta_{1}^{(C O L S)} x_{1 n}+\cdots+\beta_{m}^{(C O L S)} x_{m n} \\
u_{n}^{(C M)}=\beta_{0}^{(C M)}+\beta_{1}^{(C M)} x_{1 n}+\cdots+\beta_{m}^{(C M)} x_{m n}
\end{gathered}
$$

The first line presents the traditional Ordered Probit estimates. The second line presents the POLS estimates. Both estimates are only based on assigning ordinal significance to the responses. The third and fourth line corresponds to the COLS- and CM-methods. The last two methods assume a cardinal significance of the responses. Due to their cardinality we can interpret the values $u^{(C O L S)}, u^{(P O L S)}$ or their normal transforms as happiness levels. As the four methods are aimed to estimate the same net of indifference curves, we expect the same trade-off ratios, e.g., $\beta_{1}^{(O P)} / \beta_{2}^{(O P)} \approx \beta_{1}^{(C M)} / \beta_{2}^{(C M)}$. This was indeed found in Van Praag and Ferrer-i-Carbonell (2004, Section 2). For dummy variables and intercepts these approximate equalities do not hold. 
Through the Income Evaluation Question (IEQ) we find a fifth estimated equation

$$
u_{n}^{(I E Q)}=\alpha_{0}^{(I E Q)}+\alpha_{1}^{(I E Q)} x_{1 n}+\cdots+\alpha_{m}^{(I E Q)} x_{m n}
$$

This equation is again estimating the same net of indifference curves. We found in Van Praag and Ferrer-i-Carbonell (2004, 2008b, Section 2) indeed as expected that $\beta_{1}^{(O P)} / \beta_{2}^{(O P)} \approx \alpha_{1}^{(I E Q)} / \alpha_{2}^{(I E Q)}$.

The conclusion must be that modern happiness economics and the older Leyden School are different approaches to the same question. What are the differences between both?

The two main differences are:

- The Leyden School approach focused on the estimation of Individual Welfare Functions of Income (WFI) which refer to financial satisfaction. Modern happiness economics focuses on satisfaction with life as a whole, although there are excursions to domain satisfaction, notably to job and health satisfaction.

- The IEQ of the Leyden School taps information on the whole utility function, that is, income levels associated with various levels of satisfaction. The stimulus is the level $U_{i}$ of financial satisfaction and the response is the corresponding income level $c_{i}$. The life satisfaction question asks for only one response. The stimulus is own income, and the reaction is the satisfaction with own life as a whole.

On one hand the Leyden method may be seen as more restricted than the satisfaction question approach as it lends itself hardly for estimation of other than financial satisfaction functions, say, job or health. However, see Van Praag et al. (1988) for some other applications, On the other hand the Leyden approach may be seen as richer as it delivers not a point but a whole satisfaction curve per individual respondent. Nevertheless, there is enough similarity between the two to treat them simultaneously in the following pages. The main question which has been posed in the two lines of research is what factors determine individual satisfaction levels. This will be worked out in the next pages, where we tap from the two sources simultaneously. 


\section{8}

\section{Reference Groups}

Individuals derive their norms and values for a large part by comparing their situation to that of others. Consequently, whether persons are content with their food situation, their housing situation, their social situation, their income or their life as a whole, to mention only a few things, depends to a large extent of the situation in that respect of others in the social neighborhood or reference group. The best example is that of income. If everybody in your comparison group earns more than yourself, then you feel probably discontent with your income and if you are the richest of the street, you feel well-off and more satisfied.

The first implication of the existence of the reference mechanism is obviously that the evaluation by an individual of his or her situation is partly relativistic, depending on his social environment. The second implication is that the degree of social transparency of the society affects the feelings of well-being in society.

Within the framework of happiness economics the first one who discovered traits of the reference mechanism was Easterlin (1974). He compared happiness between different countries and he found that there was not much difference in average happiness, although the countries observed were strongly different in their average income. Within 
each country it was found that happiness was positively related with income. The conclusion from this finding is that income differences that are observed matter for well-being, but that differences that are not observed do not matter. This finding has later on been called Easterlin's paradox. In recent literature there have been put question marks to the validity of the paradox, as it was found that average happiness in some poorer countries was lower than in some richer ones. Examples of this refutation of Easterlin's paradox are found in Deaton (2008), Stevenson and Wolfers (2008a,b), and Sacks et al. (2010). Hence, it is doubtful whether the paradox in its original form is tenable.

In the Leyden tradition the first sign of awareness of the reference group was found in Van Praag (1971a,b). In Van Praag (1976) we find an estimated equation

$$
\begin{array}{ccc}
\mu(c)=1.92+0.13 \ln [f s(c)]+0.50 \ln [y(c)]+0.30 \mu_{y}(c) & \left(\bar{R}^{2}=0.649\right) \\
(0.44)(0.02) & (0.01) & (0.05) \\
\sigma^{2}(c)=0.13+0.82 \sigma_{y}^{2}(c) & & \left(\bar{R}^{2}=0.024\right) \\
(0.02)(0.15) & N 2774
\end{array}
$$

where the parameters $\mu$ and $\sigma$ of the individual welfare function are explained by family size, own net household income and the log-median and standard deviation of the income distribution of the individual's reference group. This result stems from the research paper by Kapteyn et al. (1978).

We see that there is a strong reference effect of about 0.30 . The authors called this effect the reference drift. As we saw above what really counts is the term $(\ln (y)-\mu) / \sigma$. Consider the coefficients of $(y(c)-\mu(c))$ in the equation above. Let us consider the thought experiment that all incomes in the reference group increase by the same percentage and your own income by the same fraction as well. Moreover, assume that preference and reference drift effects would not add up to 0.8 as estimated above but to 1 . In that case $(\ln (y)-\mu) / \sigma$ would remain constant. In other words, the joint result of preference and reference drift would be that feelings of welfare remain constant if everybody's income rises by the same percentage. The empirical estimate above shows that in reality the leakage is not $100 \%$ but about $80 \%$. 
Nevertheless, the phenomena as such are very relevant for the evaluation of income distribution policies. We refer to Kapteyn and Van Herwaarden (1980) for the application of this model to a quest for the optimal income distribution, where they take both the preference and the reference drift phenomena into account.

Although this approach is intuitively appealing, there is still a nasty problem. How is the reference group of an individual defined? There are two ways that can be taken. The first way is to define for each individual a reference group as consisting of all individuals with the same age, education, living area, etc. Then the reference income is defined as the average income or the median income in that group. This approach is a bit arbitrary in the sense that we define the reference group beforehand instead of that we derive the composition of the reference group from the data. It is the latter way that is chosen in Kapteyn et al. (1978), which is the basis for the equation above. In a much more sophisticated way a similar model is estimated on panel data by Van de Stadt et al. (1985). For an alternative model see Van Praag (1981), also described in Section 8 of Van Praag and Ferrer-iCarbonell (2004). However, most models using reference group effects depart from the idea of an exogenously defined reference group. We mention especially Hagenaars (1986).

Actually, the work considered before was focused on financial satisfaction, as it has been based on the Leyden welfare function. In modern happiness economics the main attention is on satisfaction with life as a whole. Again we may ask whether the situation of members of my reference group influences my subjective evaluation of my own situation. More generally, we may put the question with respect to each separate domain of life as well. However, in modern happiness economics the focus is on life as whole. The reference situation is described only in terms of income. The reference group is exogenously defined.

It may be conjectured that reference group effects may be found for all aspects of behavior. The evaluation in terms of satisfaction with our financial situation is just one example of a general sociological phenomenon. For instance, clothing behavior is determined to a large extent by imitation of the reference group, which does not have to be identical with my income reference group. 
Table 8.1. Reference income effects on individual life satisfaction Germany.

\begin{tabular}{lccccccccc}
\hline & \multicolumn{2}{c}{ Benchmark } & & \multicolumn{2}{c}{ First specification } & & \multicolumn{2}{c}{ Second specification } \\
\cline { 2 - 3 } & Estimate & $t$-Value & & Estimate & $t$-Value & & Estimate & $t$-Value \\
\hline Family income & 0.248 & 16.67 & & 0.248 & 16.80 & & 0.100 & 1.49 \\
$y_{\text {ref }}$ & - & - & & -0.226 & -3.47 & & - & - \\
$y-y_{\text {ref when rich }}$ & - & - & & - & - & & 0.079 & 1.17 \\
$y-y_{\text {ref when poor }}$ & - & - & & - & - & & -0.189 & -2.83 \\
Pseudo- $R^{2}$ & 0.080 & - & & 0.080 & - & & 0.080 & - \\
\hline
\end{tabular}

Source: Ferrer-i-Carbonell (2005).

Satisfaction with life as a whole is naturally affected as well by the reference group. Hence, it seems obvious to include average values of the reference group, especially average income, as an explanatory variable into the life satisfaction equation. We mention especially the study by Luttmer (2005) who defines the reference group as people living in the geographical neighborhood of the individual. Ferrer-i-Carbonell (2005) considers a German sample, where she defines the reference groups on the basis of five education groups, five age brackets and two regions. For each subgroup the average log-income $y_{\text {ref }}$ is defined. Ferrer found the following results in Table 8.1, where we only concentrate on the now relevant effects. For the complete specification we refer to the original paper.

We see from the first specification that next to income the reference income has a definitely negative effect. If individuals are aware that on average other people in their reference group earn more this has a negative effect on subjective well-being. This may be split up by adding for people below and above the reference income the distance between their own income and their reference income. For the relatively poor we find a strong negative effect, but the relatively rich are only moderately pleased by the fact that most members of their reference group earn less. Similar effects are found by Stutzer (2004) and Luttmer (2005). Daly and Wilson (2011) use suicide data and empirically find that suicide risk depends, controlling for own income and other individual characteristics, on the income of the reference group. Senik (2004) studies Russian data and finds there a positive reference effect. This is interpreted by Senik (2004) as signaling that an upwards motion in the reference group is possible. 
All in all we conclude that there is clearly an effect of reference groups. However, up to now the only reference variable is income, which may be a very narrow interpretation of the reference group, being rather one-dimensional. Moreover, the reference group is up to now exogenously defined according to intuition and not derived from data analysis.

A more sophisticated model has been recently presented by Van Praag (2010). However, it is not yet empirically implemented and estimated, and it seems hard to find or to create a suitable data set.

Another recent line of research focuses on understanding how individuals form their reference groups. Up until now all empirical literature has defined the reference group as exogenous, for example, by looking at individuals of same education level or age. Nevertheless, recent evidence supports the already existing theoretical claims that reference groups are endogenously formed. This evidence comes mainly from two studies based on two different question modules introduced into the 2006/2007 wave of the European Social Survey and on the 2008 wave of the German Socio-Ecoonomic Panel Data. Clark and Senik (2010) used the questions included in the European Social Survey in which respondents were asked to whom and how much they compared themselves with others. Clark and Senik's (2010) paper reports that the intensity of income comparisons decreases with income (i.e., richer individuals compare less), people who compare the most are the least happy, and that there is a large diversity of groups (for example, colleagues and family members) to which individuals compare themselves. Mayraz et al. (2009) report the results from German SOEP-data and as Clark and Senik (2010) find that own happiness is an important determinant of the intensity of comparisons, i.e., comparisons are endogenous. 


\section{Memory, Anticipation and Adaptation}

It is obvious that life satisfaction is not only based on the life conditions of the moment. Past events play a role in the norms by which present life conditions or rather life as a whole is evaluated. And we may even surmise that anticipations on the future play a role as well. The straightforward way to investigate this idea is to analyze a longitudinal data set, where we introduce into the happiness equation lagged variables. Let $x$ stand for monthly household income and let happiness depend on present and past incomes as

$$
u_{t}=\beta_{0} x_{1 t}+\beta_{1} x_{1, t-1}+\cdots+\beta_{k} x_{1, t-k}+\gamma_{0}
$$

If all $x^{\prime} s$ are equal to $\bar{x}$, we have

$$
u_{t}=\bar{x} \cdot \sum_{i=0}^{k} \beta_{i}+\gamma_{0}=\bar{x} \cdot \tilde{\beta}+\gamma_{0}
$$

This is the stationary case and $\tilde{\beta}=\sum_{i=0}^{k} \beta_{i}$ is the stationary effect of the variable $x$ on happiness. Consider now a permanent change in income, say from $\underline{x}$ to $\bar{x}$ at moment $t$. Then we have

$$
\begin{aligned}
u_{t} & =\beta_{0} \bar{x}+\beta_{1} \underline{x}+\cdots+\beta_{k} \underline{x}+\gamma_{0} \\
u_{t+1} & =\beta_{0} \bar{x}+\beta_{1} \bar{x}+\cdots+\beta_{k} \underline{x}+\gamma_{0}
\end{aligned}
$$


Happiness increases from $t-1$ to $t$ by $\beta_{0}(\bar{x}-\underline{x})$. From $t-1$ to $t+1$ the accumulated change is $\left(\beta_{0}+\beta_{1}\right)(\bar{x}-\underline{x})$ and so on. Assuming the $\beta$ 's to be positive and decreasing, we see that there is an instantaneous change in happiness, but that in the second period there is a further increase. The increases continue until the income change is $k+1$ months in the past. The final value is $\bar{x} \cdot \tilde{\beta}+\gamma_{0}$.

It is by no means sure that all the effects will be positive. For simplicity let us assume $\beta_{0}>0, \beta_{1}<0, \beta_{2}=\beta_{3}=\cdots=0$. In that case satisfaction in period 1 is less then in period 0 when the income increase occurred. The accumulated effect after two periods is $\left(\beta_{0}-\beta_{1}\right)(\bar{x}-\underline{x})$. In the case that $\left(\beta_{0}-\beta_{1}\right)=0$, the adaptation to the new income level is complete and there is no lasting increase in happiness. All changes in income would have only a temporary effect. It is obvious that the same story can be told with respect to other satisfaction determinants like employment status, marital status, etc. What is the effect over time of changes, either incidental or permanent, on life satisfaction?

There is a fundamental discussion on this point between happiness economists and psychologists. Up until this decade, most psychologists argued that there is a general baseline satisfaction level. Changes in underlying conditions may cause changes in satisfaction, but over time individuals will 'rebounce' to the baseline that depends on their individual character. This was called the 'set-point 'theory. More recently, however, it has become evident that the set-point theory needs at least some revision, as individuals are not seen to adapt to everything (see for example, Lucas et al., 2004).

In their classic article on adaptation, Brickman and Campbell (1971) argued that people are confined to a hedonic treadmill - they are doomed to experience stable levels of well-being because, over time, they adapt to even the most extreme positive and negative life circumstances. This idea has received considerable empirical support. Most cross-sectional studies of life satisfaction and long-term emotional levels find that objective circumstances account for surprisingly little variance in reports of subjective well-being (SWB). Even people who have won large sums of money in lotteries and people who have experienced debilitating injuries appear not to differ strongly from the average person (Brickman et al., 1978). Thus, although people may react 
strongly to life events, the evidence suggests that they eventually return to their initial levels of happiness. The hedonic treadmill theory has had a profound effect on SWB research (for general reviews of the area, see Argyle, 1987; Diener et al., 1999; Kahneman et al., 1999; Lyubomirsky, 2001; Myers, 1993). In fact, the hedonic treadmill is almost identical to the preference drift phenomenon from the Leyden school. However, the perfect set-point assumption is tantamount to a preference drift rate of 1.0, while Leyden School estimates consistently are in the range between 0.5 and 0.6 .

The theory's supporting evidence has led some researchers to conclude that adaptation is quick, complete, and inevitable and that most of the long-term stable variance in SWB can be accounted for by personality and genetic predispositions rather than by life circumstances (Lykken and Tellegen, 1996). According to this idea, people have happiness set-points to which they inevitably return following disruptive life events (Headey and Wearing, 1989; Larsen, 2000; Williams and Thompson, 1993).

Economists and recently psychologists on the contrary do not automatically accept set-point theory. The proof of the pudding is clearly in the eating, that is in the empirical evidence that the sum of the temporary effects $\sum_{i=0}^{k} \beta_{i}$ equals zero or not. An authoritative study is by Clark et al. (2008). Their study generalizes the idea of determinants by looking at the effects of other major life events like marriage, divorce, widowhood, birth of child and layoff. They do not include income changes. They generalize in a second way by including not only past events but also the anticipations on future events. Indeed, individuals frequently have already an expectation that they will become divorced, married or lose their job. Diener et al. find that 'they cannot reject the hypothesis of complete adaptation to marriage, divorce, widowhood, birth of child and layoff. However, there is little evidence of adaptation to unemployment for men'. All these studies find that the range in time over which non-zero effects can be measured is about four years in the past and in the future. Frijters et al. (2011a) use quarterly data from the Household, Income and Labour Dynamics in Australia (HILDA) to study the dynamics of happiness and its interaction with important life events. The authors argue that the use of quarterly data 
allows them to understand adaptation and expectations in a way that is not possible with yearly data. They found important evidence in favor of the existence of adaptation and expectations as well as of selection.

Finally we mention a related approach in the Leyden literature by Van Praag (1988a), which is based on a cross-section where artificial income histories are introduced by using an estimated earnings function. There a weight distribution over the time axis is defined, including weights on the past and on the anticipated future. It is found that those distributions vary with individual characteristics, notably with the age of the individual, where young and old individuals are much more past-oriented than individuals in midlife who are more futureoriented. Part of it has been summarized in Section 7 in Van Praag and Ferrer-i-Carbonell (2004, 2008a,b). 
Climate and Other External Effects

We know that individual happiness is affected by income, health and a host of other variables, as listed above. Not yet considered are climate effects. We may conjecture that temperature, hours of sunshine, rainfall, etc. will have an effect on happiness. This has indeed been found. The first studies we know of were in the Leyden School tradition by Van Praag (1988b) on Western European climate differences, and by Frijters and Van Praag (1998) on climate differences on the SovietRussian territory. Rehdanz and Maddison (2005) apply basically the same method on a selection of countries where they do not consider individual happiness but national averages of happiness.

Obviously, these differences are not consciously felt by individuals in the various countries. The life satisfaction function which is estimated is the experienced utility function, which already accounts for adaptation to climate. Or said otherwise, the function describes what an individual in France feels about the French climate and how the American living in Alaska evaluates the Alaskan climate. If we ask the French individual to evaluate the Alaskan climate, our estimated function does not give a correct prediction of this evaluation, as the French 
individual has not adapted himself to the Alaskan climate and is likely to exaggerate the displeasure of living in the Alaskan climate. Here we face again the difference between the decision utility function and the experienced utility function, which we also encountered when discussing the preference drift/hedonic treadmill phenomenon.

There is a second point which we have to keep in mind when evaluating adaptation processes. Consider an individual who would earn $y_{\mathrm{F}}$ in France and $y_{\mathrm{A}}$ for the same work in Alaska. Then probably his Alaskan income would be higher than his French income and the difference is probably a compensation for the cold and other climate differences. In short, a part of the utility differences is compensated by income and price differences through the market. If at both places satisfaction would be equal, it is obvious that no additional monetary compensation is needed to equalize satisfaction. If not, the income difference needed to reach satisfaction equality may be interpreted as a residual compensation. It is not the whole cost of the climate difference between both places.

A similar exercise has been applied by Van Praag and Baarsma (2005) for the case of the Amsterdam region to find out whether air plane noise reduces the life satisfaction of inhabitants. Also here the satisfaction loss caused by noise of airplanes is partly compensated by lower rents and house prices for houses, lying below the air-lanes.

This method has some advantages compared to the competing method of hedonic prices as developed by Rosen (1974) and Roback (1982). The problem with the hedonic price method becomes clear when we consider the method in detail. In its most simple variant it is based on estimating how prices of a specific good, not only housing or land, but also wine (see, e.g., Nerlove, 1995), depend on external non-priced variables like temperature, unemployment, availability of roads, infrastructure, etc. It is assumed that the same variables figure in the individual utility function and that individuals are moving to the optimal place. In that case we may indeed assume that the price surface is tangent to the indifference surface and hence that the slope coefficients of both surfaces are identical. It follows that the relative subjective trade-offs between variables that determine utility equal the objectively measurable price trade-offs, estimated from observing the 
62 Climate and Other External Effects

price relationship. The snag is in the assumption that consumers are in equilibrium, which is unverifiable, and which is rather dubious in cases concerning housing. We refer to Van Praag and Baarsma (2005) for further discussion. 


\section{1}

\section{Poverty}

In social policy, poverty is a key concept. In modern policy it is taken for granted that one of the essential tasks of the state is to guarantee a minimum livelihood to those who cannot provide it for themselves. This minimum level is frequently called the poverty line or minimum income, also denoted here by $y_{\min }$. There are two mainstreams to be distinguished in the poverty literature. One is the traditional one, which pretends that it is possible to establish a minimum basket of commodities and services. Then we may calculate the value of that basket at market value, and, voilà, we have the minimum income level or poverty line. This is actually still the method which is used in most civilized countries. This approach is questionable for at least two reasons. First, how to define such a minimum basket? This is done on the basis of calorimetrics or on the basis of a seemingly more sophisticated decision of a commission of experts and/or politicians. It is obvious that the so defined poverty line will vary a lot between rich and poor nations. It is unconsciously relativistic, but this method is also based on arbitrariness. For who knows whether individuals, qualifying for the basket, really qualify themselves as poor, and inversely, whether people qualified as non-poor qualify themselves as non-poor? The relativistic nature 
of poverty is openly recognized by, e.g., the EU and OECD that define the poverty line at $60 \%$ of the median income in the country. An additional problem is how to correct for different family sizes, etc. Finally, we have to recognize that poverty might be a multi-dimensional issue which cannot be repaired by giving only money.

In the subjectivistic literature there are two attempts to define poverty. Both have been proposed in the seminal paper by Goedhart et al. (1977). In that paper there are two poverty lines suggested. The first is based on the Individual Welfare Function approach. Let $U_{n}(y)$ stand for $n$ 's utility function of income, then we choose a specific level, say 0.4 or 0.5 as corresponding to the beginning of the poverty status. Remember that 0.4 corresponds to a verbal description of a 'bad income' on the Income Evaluation Question. Then the poverty line of $n$, say $y_{\min , n}$, is found by solving $U_{n}\left(y_{\min , n}\right)=0.4$. Things are becoming complex, as $U_{n}(y)$ depends on personal parameters $\mu$ and $\sigma$, which entails that each individual would have its own poverty line $\ln \left(y_{\min , n}\right)=\frac{u_{0.4}-\mu_{n}}{\sigma_{n}}$. This is politically seen as impossible. Fortunately, it has been found that $\mu\left(y_{n}\right) \approx \beta_{0}+\beta_{1} \ln \left(y_{n}\right), \beta_{1}>0$. That is, the welfare function shifts with rising income to the right, the so-called preference drift phenomenon. Consider now the solution of $U_{n}\left(y_{\min } ; \mu\left(y_{\min }\right)\right)=0.4$. It is the solution $y_{\min }$ of the log-linear equation

$$
\frac{\ln \left(y_{\min }\right)-\beta_{0}-\beta_{1} \ln \left(y_{\min }\right)}{\sigma}=u_{0.4}
$$

where we assume $\sigma$ constant over $n$. Now it is evident that there is one solution $y_{\min }$ and that

$$
\begin{array}{ll}
U_{n}\left(y_{n} ; \mu\left(y_{n}\right)\right)<0.4 & \text { if } y_{n}<y_{\text {min }} \\
U_{n}\left(y_{n} ; \mu\left(y_{n}\right)\right)>0.4 & \text { if } y_{n}>y_{\text {min }}
\end{array}
$$

It follows that the solution $y_{\min }$ can be considered as the general poverty line. The obvious advantage of this definition is that it is grounded on the individual opinions; if we have a representative sample of the population, $y_{\min }$ may be considered as the national poverty line at level 0.4 .

There is a second advantage: we saw that in fact $\mu$ depends on other variables as well, for instance, on the family size $(f s)$. It follows that 
the poverty line may be differentiated with respect to family size $f s$ and other relevant variables.

A second but related approach, also suggested by Goedhart et al. (1977), departs form the so-called Minimum INcome Question (MINQ). Its wording is

What is in your opinion the minimum amount of income that your family in your circumstances would need to be able to make ends meet?

That would be $\$ \ldots . . . . .$. . per month.

It was found in Goedhart et al. (1977) that the answer to this question which we will call $\hat{y}_{\min , n}$ depends on the same variables as $\mu$ according to a $\log$ linear equation like $\hat{y}_{\text {min, } n} \approx \sim \alpha_{0}+\alpha_{1} \ln \left(y_{n}\right)$, where the coefficients (except $\alpha_{0}$ ) are almost equal to those of the $\mu$-equation. In a completely similar way the corresponding poverty line is derived. The corresponding $U$-level is found to be about 0.55 . The advantage of this procedure is that one does not need posing the rather elaborate IEQ and accepting the theory and interpretation of a utility function but can do with the simpler MINQ. It implies that we can derive the poverty line corresponding to only one utility level and that we do not know beforehand which utility level it corresponds to. The IEQ leads to more calibration of the answers than asking just one level. The product of the first approach is sometimes called the Leyden Poverty Line (LPL) and the product of the second approach the Subjective Poverty Line (SPL). Both methods have been frequently applied not only on western countries, but also on Russia, China and other countries to calculate subjective poverty ratios and to discover which social types have great poverty risk. However, the two methods, as far as we know, have never been accepted for producing the official poverty line of a country up to now. For more on this see Hagenaars (1986), Colosanto et al. (1984), Van Praag et al. (1980), Hagenaars (1987), and for more recent applications Bautista (2008), and Gustafsson et al. (2004).

It is obvious that the same method may be applied on life satisfaction questions. Interpreting the satisfaction function as a cardinal utility function between 0 and 1, it may be estimated by the COLS- or 


\section{Poverty}

CM-method. Setting the satisfaction function at 0.4 or any other value we find an indifference surface corresponding with the specific poverty level. We may call it the poverty border. Notice that the poverty border is a multi-dimensional poverty line. It depends on all characteristics on which life satisfaction depends. We also refer to Van Praag and Ferreri-Carbonell, (2001), Van Praag and Ferrer-i-Carbonell (2004, 2008a) and for a related approach to Pradhan and Ravallion (2000). 


\section{Macro-economic Determinants of Happiness}

There are a number of studies that empirically estimate the importance of other macro-economic variables for individuals' happiness. If the objective function of the social planner is a measure of social welfare, subjective measures of happiness can be used as an important source of information. Di Tella et al. (2001) estimate a negative and statistically significant correlation between happiness and both unemployment and inflation rate. In their paper they report that the effect of unemployment is larger: the relation between the two rates ranges between 1 and 1.7, depending on the country and year. Clark et al. (2010) find that the importance of regional unemployment for males' happiness negatively depends on their own job prospects. Di Tella et al. (2003) find a positive effect of GDP and unemployment benefits on reported happiness and a negative effect of unemployment rate. The empirical correlation between individual reported happiness and GDP per capita has been frequently investigated. While in the first studies authors found a weak relationship that tended to flatten beyond a threshold (Easterlin, 1974; Di Tella and MacCulloch, 2008), recent evidence has disputed this finding (Stevenson and Wolfers, 2008a; Sacks et al., 2010). 


\section{Macro-economic Determinants of Happiness}

There is also a string of literature that has empirically estimated the impact of other macro-variables on individuals' happiness, For example, there are a few studies looking at the importance of the environment (pollution). These studies have generally found that the concentration of pollutants in the region where the individual lives has a negative impact on self-reported happiness (Frey et al., 2010; Luechinger, 2009). Metcalfe et al. (2011) studied the impact that 11/09 had on happiness reports of UK respondents and concluded that respondents who were interviewed after September 11 reported lower satisfaction scores than those who were interviewed just before. 
Behind this title two interesting questions are hidden. The first one is whether there is an effect of income inequality, wealth inequality or inequalities with respect to other features in society on the subjective feelings of happiness in that society. The second question relates to the distribution of happiness in a society. For, just like income is distributed in a society and we can define inequality of income for that income distribution, it seems conceivable that we can define and study inequality of happiness in a society. We shall consider the two questions successively.

\subsection{Effect of Inequality on Happiness}

The first question is considered by a.o. Alesina et al. (2004), Graham and Felton (2006), Smyth and Qian (2008), and Grosfeld and Senik (2010). Alesina et al. (2004) assume that income inequality (measured by the Gini index) in the country of the respondent has an effect on happiness. The idea is that a rising inequality will reduce life satisfaction. They use a large U.S. database where inequality is differentiated with respect to the separate states, thus creating differences in 
observed inequality. Next to it they utilize a comparable European data set. Their question is whether the state - Gini's are significant determinants of life satisfaction and secondly, whether there is a difference between Europe and the U.S. They find indeed mostly a negative effect, but not always.

Graham and Felton (2006) repeat this exercise for a recent LatinAmerican data set. As income data are rather unreliable they use wealth class estimates. They did not find significant results, which may be ascribed to the rather rough data and perhaps the specific definition of inequality by the Gini-index. A more productive road which they used was to compare individual wealth with average wealth in the country. This led to the distinction of a significant wealth effect and a reference effect. Smyth and Quian repeated the previous studies where they instrumented inequality by the individual's perception of inequality as represented by the variable INEQUALITY. This is an ordered variable derived from the question: "Please evaluate the degree of fairness in the distribution of income" with response classes: $1=$ "not too serious" to $5=$ "extremely". Actually, this is a rather subjective variable itself. Again they find a negative effect.

\subsection{An Index of Happiness Inequality}

Let us now consider the second connection in which inequality is relevant. Then we look for an index to characterize the inequality of the distribution of individual happiness in a population. Like any inequality index such an index is rather arbitrary. The only thing we can say with certainty is that there is no inequality if everybody enjoys the same degree of happiness. However, let us assume a happiness distribution $\mathscr{U}=\left\{U_{1}, \ldots, U_{N}\right\}$ over the population where the distribution is unequal, then we have to make ad hoc assumptions. If we would stick to the ordinal character of happiness statements, then we do not know what to make from the inequality between three individuals 1, 2 and 3 where $U_{1}=4, U_{2}=7, U_{3}=9$. It is obvious that individual 2 is happier than 1 and individual 3 than 2 , but what about the two differences in happiness? Is the jump between 7 and 4 larger than between 9 and 7 . Or said otherwise, is the inequality in happiness between 4 and 7 greater 
than the inequality in happiness between 7 and 9? This can only be answered if we assign a cardinal significance to the responses. If we do accept cardinality, the answer can be given. Then it becomes also possible to define average happiness as $20 / 3$. In practice many empirical studies present average happiness figures as a matter of course. One of the first examples was the famous study by Easterlin (1974), who compared average happiness per country for 19 countries over a period of several decades. But if we accept cardinal significance for the numerical answers on happiness questions, it becomes also possible to define inequality indexes. The first idea which comes into mind is to consider the standard deviation of happiness, that is, $\sigma(U)$. This is the way, which is taken in Kalmijn and Veenhoven (2005) and in Ott (2005).

It will be obvious that many other measures, originally used to measure income inequality, may be used in the present context for the measurement of happiness inequality. Actually, just like in income inequality investigations we frequently consider the standard deviation of log-incomes instead of the standard deviation of incomes, we might replace the response $U$ by $\ln (U)$ and consider the standard deviation of the distribution of log- happiness.

In this vein Van Praag and Ferrer-i-Carbonell (2008b) considered the happiness function $U(x)$ as a distribution function and consider the logarithm of the density function or in economic terms the marginal utility function. They define the inequality index as the standard deviation of the logarithm of the marginal utility function. It can be shown that if utility would depend on income only, this measure coincides with the standard deviation of log-incomes.

An important paper in the literature of inequality is Stevenson and Wolfers (2008a) who examine how happiness inequality has evolved in the US over the last 40 years (1972-2006). These authors report that although happiness has not increased, inequality in happiness has decreased very much since the 1970s. This comes from important changes in the happiness levels of different groups in society: while the black-white gap has decreased, the opposite is true for differences in education. Since income inequality has increased, the decrease in happiness inequality reflects, according to these authors, the importance of non-pecuniary things for happiness. 


\section{4}

\section{Satisfaction and Vignettes}

Up to now, we have considered satisfaction as measured by a rather simple question where life satisfaction had to be evaluated by the respondent in terms of either a number on a numerical scale or a verbal evaluation like 'good', 'bad', or 'rather happy', 'not so happy'. The same methodology is applicable to domain satisfactions as well, e.g., job satisfaction or health satisfaction. Rather recently, another methodology has come up to measure satisfaction and especially domain satisfactions, which we will now consider shortly. It is the vignette methodology, also known as conjoint measurement. It is most easy to explain the method by giving an example of a vignette. We give an example on job satisfaction, borrowed from Ferrer-i-Carbonell et al. (2010). In Figure 14.1 we see a description of a hypothetical job and below the description an invitation to rate this job on a numerical scale.

The crucial difference between this type of questioning and the satisfaction questions considered thus far is that this vignette question aims at getting information on the satisfaction evaluation of fictitious jobs, while the satisfaction question only aims at getting information on the respondent's present real job. At first sight this looks like a tremendous extension of the range for satisfaction questions. In the 


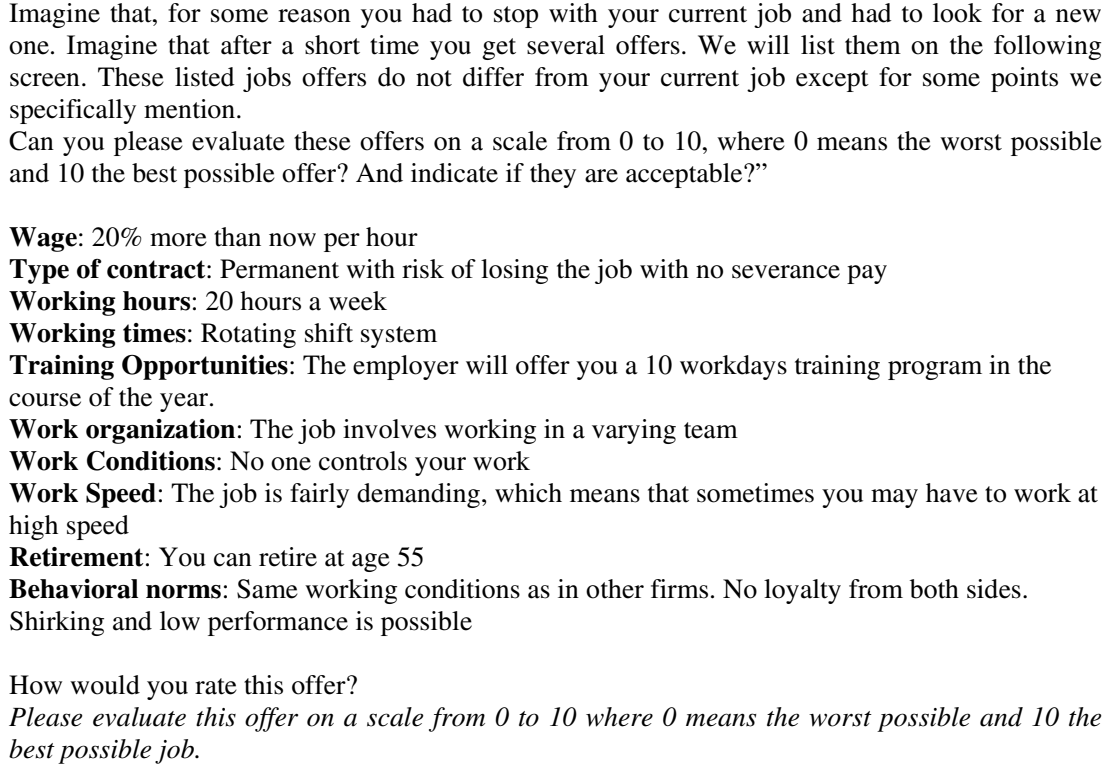

Wage: $20 \%$ more than now per hour

Type of contract: Permanent with risk of losing the job with no severance pay

Working hours: 20 hours a week

Working times: Rotating shift system

Training Opportunities: The employer will offer you a 10 workdays training program in the course of the year.

Work organization: The job involves working in a varying team

Work Conditions: No one controls your work

Work Speed: The job is fairly demanding, which means that sometimes you may have to work at high speed

Retirement: You can retire at age 55

Behavioral norms: Same working conditions as in other firms. No loyalty from both sides.

Shirking and low performance is possible

How would you rate this offer?

Please evaluate this offer on a scale from 0 to 10 where 0 means the worst possible and 10 the

best possible job.

Fig. 14.1 Example of a vignette.

present case the respondent becomes not only able to evaluate his own job, described by a vector $x_{\text {own }}$, but a more-dimensional continuum of jobs $x$. This enables us, in theory, to estimate per individual a job satisfaction function $V(x)$. The same technique is available to estimate health satisfaction functions on vignettes of different health situations, and so on.

The vignette methodology as such (also known as conjoint analysis) is extensively used in psychology and marketing (Green and Srinivasan, 1978; Louviere et al., 2000). In economics some of the first applications have been in Van Beek et al. (1997) and Van Ophem et al. (1999).

King et al. (2004) were the first to suggest anchoring vignettes as an additional tool to test whether satisfaction responses are comparable between respondents belonging to different cultures. They supplied different people with the same vignette and observed whether they evaluated it equally or differently. Indeed, the question is justified whether respondents belonging to different cultures will evaluate the same vignette by the same number or the same evaluation. There may 
be two causes for a divergence. First, it may be due to the fact that, e.g., the evaluation 'good' has a different emotional connotation, say, in Italy or in Sweden. It is well-known that Southern-Europeans are more outspoken in their evaluations than people from Northern Europe. The second point may be that the situation, described by the vignette, is differently evaluated, according to the culture the respondent is living in. For instance, the same income level may be felt as rather poor in the USA and as rather rich in India. If people in different cultures tend to evaluate the same vignette identically, we speak of vignette equivalence. Kapteyn et al. (2007), Angelini et al. (2008), Bago d'Uva et al. (2009), and Voǒková and Hullegie (2010), and a working paper by Ferrer-i-Carbonell et al. (2010) applied and tested the technique on its validity. It seems that there is serious doubt on the assumption of vignette equivalence. It would follow that vignette evaluations are mostly culture-bound and not usable for international comparisons.

The second question is whether evaluations by means of vignettes are consistent with answers on satisfaction questions. More precisely, if somebody's own situation is pictured by a vignette $A$, can we expect that evaluation of the vignette $A$ will be the same as the answer on the satisfaction question asking for an evaluation of the own situation. If yes, this outcome is called response consistency. Also here the outcomes from the same papers are putting response consistency into doubt. Our conclusion is that the two measurement methods seem to measure different utility functions. The vignette evaluation reminds us of the decision (or ex ante) utility function, while the real life satisfaction question reveals the experienced (true) utility function in the terminology of Kahneman et al. (1997).

Summarizing the vignette technique cannot be considered as a substitute or an extension of satisfaction questions, but it is a technique on its own, which can be very useful indeed. 


\section{The Significance of Happiness Economics for Normative Economics}

In the previous sections, we have almost exclusively focused on the question which factors, personal, psychological or environmental, codetermine feelings of satisfaction, either with life as a whole or with specific domains of life. This is positive economics, or more generally positive science. The final and not unimportant question is now in how far we can use the acquired knowledge for economic policy, that is, whether we can derive norms from happiness economics to be applied in economic policy. Is transferring our results to normative economics warranted?

As we all know this is a glibbery question. According to Fleurbaey (2008) most of the results in normative economics, or as it is also called welfare economics, up to now are negative results, stating that specific things were impossible with the famous Arrow impossibility theorem as the nadir of that branch of economics. Fleurbaey (2008) speaks 'of the repeated failure to provide conclusive results and its long-lasting focus on impossibility theorems. But there has also been a persistent ambiguity about the status of normative propositions in economics. The subject matter of economics and its close relation to policy advice make it virtually impossible to avoid mingling with value judgments'. 
Might it be that happiness economics may be the instrument to fill in this gap in present normative economics? In a sense yes, and in another sense no.

When looking in this question we touch again on the question whether it is admissible to interpret the results in a cardinal way or only in an ordinal way.

Let us at first look from the restrictive standpoint that we are only observing indifference curves. That is, we stick to ordinal interpretations. We start to consider the question by means of a practical example: family size and satisfaction. We draw our example from Van Praag et al. (2010). There we analyzed life satisfaction and financial satisfaction for an Israeli survey on the Jewish subpopulation. We reproduce here in Table 15.1 the present context relevant part of the estimations.

We consider first the columns of the second specification. We see here that family size has a strong negative effect on financial satisfaction and a non-significant small negative effect on satisfaction with life as a whole. That the effect of children on the perception of which income is good is negative is well-known. Having children is costly. As we saw before, it is even possible to calculate exactly the income compensation

Table 15.1. Life satisfaction and financial satisfaction for Jews in Israel, 2006.

\begin{tabular}{|c|c|c|c|c|}
\hline & \multicolumn{2}{|c|}{ Life Satisfaction } & \multicolumn{2}{|c|}{ Financial Satisfaction } \\
\hline & Specif. 1 & Specif. 2 & Specif. 1 & Specif. 2 \\
\hline \multirow[t]{2}{*}{ Intercept } & $11.392^{*}$ & $11.004^{*}$ & $12.330^{*}$ & $12.024^{*}$ \\
\hline & (1.404) & (1.402) & (1.424) & (1.421) \\
\hline \multirow[t]{2}{*}{ Ln(income) } & $0.159^{*}$ & $0.150^{*}$ & $0.553^{*}$ & $0.545^{*}$ \\
\hline & $(0.021)$ & $(0.021)$ & $(0.021)$ & $(0.021)$ \\
\hline \multirow[t]{2}{*}{ Ln(age) } & $-6.898^{*}$ & $-6.654^{*}$ & $-9.409^{*}$ & $-9.215^{*}$ \\
\hline & $(0.769)$ & $(0.767)$ & $(0.779)$ & $(0.777)$ \\
\hline \multirow[t]{2}{*}{$\operatorname{Ln}(\text { age })^{2}$} & $0.911^{*}$ & $0.880^{*}$ & $1.282^{*}$ & $1.258^{*}$ \\
\hline & (0.103) & $(0.103)$ & $(0.105)$ & (0.104) \\
\hline \multirow[t]{2}{*}{ Ln(family size) } & -0.034 & -0.021 & $-0.270^{*}$ & $-0.260^{*}$ \\
\hline & $(0.027)$ & $(0.026)$ & $(0.027)$ & $(0.027)$ \\
\hline \multirow[t]{2}{*}{ Ln(family size $)^{*}$ Religiosity } & $0.081^{*}$ & & $0.065^{*}$ & \\
\hline & $(0.022)$ & & $(0.022)$ & \\
\hline \multirow[t]{2}{*}{ Religiosity } & 0.016 & $0.113^{*}$ & 0.033 & $0.111^{*}$ \\
\hline & $(0.022)$ & & $(0.022)$ & \\
\hline
\end{tabular}

Note: one asterisk stands for significance at the $5 \%$ level.

Source: Van Praag et al. (2010). 
needed for having one, two, or more children in order that financial satisfaction remains constant; we have to solve the equation

$$
0.545 \Delta \ln (y)-0.260 \Delta \ln (f s)=0
$$

for $\Delta \ln (y)$, where $y$ stands for gross household income and $f s$ for family size.

The compensations derived from this equation are:

$\begin{array}{ll}\text { One child } & 21 \% \\ \text { Two children } & 39 \% \\ \text { Three children } & 54 \%\end{array}$

We see that the compensation for a couple to have one child would be $21 \%$ of gross household income in order to compensate for the additional child cost, $39 \%$ for having two children and so on. These percentages are rather high in international comparison. In many states it is policy to compensate families for having children, either by giving child allowances, or by giving tax deductions. In this case the exact allowance needed for having one child would be $21 \%$ of gross income. Or to say it otherwise, a family with three children feels as much financial satisfaction as a couple without children that earns a gross household income of $54 \%$ or less. If the aim of child allowances is to neutralize the child effect, then the child allowance for the first child would have to be $21 \%$ of gross income, where the allowance is still subject to taxation. It is clear that this provides a norm for child allowances. Similar results have been found for other countries, mostly based on net income and frequently lower than the Israeli results. However, here we see already a point of discussion. The norm would provide an absolute allowance that varies with income, i.e., higher income earners would receive higher allowances than low income earners. There is a reasonable explanation for this proportional outcome: people with high incomes spend more on their children in absolute terms than low income earners. However, are income-proportional allowances acceptable to citizens or for members of parliament? In other words, the question is whether the empirical result, however realistic, is acceptable as a norm? There is no easy way to solve this problem. As we do not know the true specification, we may 
estimate a slightly different specification as well. We specify the happiness Equation (2.1), say, $y_{n}=\beta_{1} x_{1 n}+\cdots+\beta_{m} x_{m n}+\beta_{0}+\varepsilon_{n}$ differently. In the specification above we have as variables $\ln (y)$ and $\ln (f s)$. We may replace those variables by $y$ and $f s$, respectively, that is, we drop the logs. In that case we can again estimate the happiness equation and we get also $\beta$-effects, although not the same as above. We may calculate in that case the compensation amounts and we will find a constant amount of money per child, irrespective of the income level and of the rank order of the child to be compensated. Hence, we see that the norm to be derived depends critically on the specification of the underlying model. What is the better specification depends on the fit of the equation, but mostly the fit of these equations, however estimated, is very low, correlation coefficients do not differ very much, and $t$-values are large for both specifications. Here we need intuition and a feeling for what is ethically acceptable by the majority of the population for which we tend to set norms.

But there are more points on which we have to decide. In the second specification of the life satisfaction equation we see the estimates of the effects on life satisfaction. Here the family size effect is only a slight and non-significant -0.021 . It follows that family size has practically no influence on satisfaction with life as a whole. It implies, as we often see that the (negative) effect on financial satisfaction is neutralized by (positive) effects on other domain satisfactions resulting in a near-zero effect on the aggregate life satisfaction. The question which we may pose then is whether there is reason for neutralization by the state of family size differences. The norm based on financial satisfaction only would suggest yes, while the norm based on the much broader concept of life satisfaction would imply no.

And things can be even made more complex. Revisiting Table 15.1, we look at the first specifications. Here we add apart from family size an interaction variable with religiosity. This makes the size of the family size effect varying with the degree of religiosity of the individual. It turns out that highly religious Jews evaluate having children much more positively than secular Jews. Using the reasoning from above, this would imply child allowances that would vary with the religiosity of the receiver. Although the observed result that children count much more 
positively for religious Jews than for secular ones seems very plausible, the conclusion that the state should giver lower child allowances to religious than to secular Jews would be hard to swallow. In short, norms derived from happiness analysis may be unacceptable or at least, at first we have to decide what should be the structure of the norm. Do we accept that child allowances do depend on the income of the receiving family, or that child allowances are differentiated according to religiosity?

The effect of family size on financial satisfaction may also be used to correct income for differences in family size. Corrections are indeed standard practice when evaluating the income distribution of a country. EUROSTAT applies for instance the OECD-scale where the first adult counts for 1 , other adults for 0.7 and children for 0.5 . Then family incomes are rescaled by dividing each income by the number of consumer units for which that family counts. Now the scientific or empirical arguments for this equivalence scale are practically non-existent. Then it seems better we employ the information in Table 11 to correct incomes by the transformation

$$
\ln \left(y_{\text {corr }}\right)=\ln (y)-\frac{0.260}{0.545} \ln (f s)
$$

In that case the income inequality, when measured by the variance of household size corrected log-incomes becomes $\operatorname{var}\left[\ln \left(y_{\text {corr }}\right)\right]=$ $\operatorname{var}[\ln (y)-(0.260 / 0.545) \ln (f s)]$. Clearly the values of the estimated parameters will vary per country. The advantage of this correction is that it is based on empirical observations on how family size differences are felt instead of on pre-scientific intuition of experts and politicians.

If we accept that responses on satisfaction questions have a cardinal significance, and the jump from 6 to 7 equals the utility difference from 7 to 8 , at least for respondents belonging to one culture, it becomes also possible to speak of average national happiness and happiness inequality. It becomes also possible to construct taxation schedules that are based on the equalization of subjective tax sacrifices, for instance, by requiring that the tax function $t(y)$ satisfies the condition $U(y)-U((1-t(y) \cdot y)=$ constant. That is, the satisfaction loss by taxation is constant, irrespective of the gross income $y$ to begin 
with. The utility function is discretely observed by the responses to the satisfaction question.

For a very interesting contribution with respect to normative applications with relevance for legal tort compensations we refer to Oswald and Powdthavee (2008).

Obviously, as said at the beginning of this essay nobody can objectively prove or disprove that we observe (in a crude form) utility by posing satisfaction questions. There are even voices that the answers to satisfaction questions (and Leyden IEQ) may be misleading as respondents are answering strategically. For instance, with respect to financial satisfaction one might answer always worse than the situation really is to convince the authorities to give more money or to reduce taxes. With respect to job satisfaction that is frequently the subject of personnel surveys workers may tend to evaluate their job worse than it really is in order to get better job conditions. Although this might be the case for some sophisticated respondents up to now there is no sign in the literature that this is really a problem in large-scale anonymous surveys. Moreover, if such questionnaires consist of 100 or more questions, it becomes difficult for respondents to select just a few questions, say Q. 59 and 80 for strategically answering. Things are of course rather different if such questions are asked in a non-anonymous context, e.g., in face to face interviews.

Especially, as the secondary analyses yield very plausible results that conform to intuition and that are repeatedly found in similar investigations, we may assume that the satisfaction questions yield valid and reliable answers which can be used for the kind of analyses as described before. 


\section{Concluding Observations, Research and Applications for the Future}

In this essay we have made an attempt to give an introduction to the field of happiness economics. We are acutely aware that in this essay we have not given to every contributor to the field its due credits. Our reference list is certainly not exhaustive either. However, it seems to us that readers from this beginning may have got an idea about the strengths and weaknesses of this approach and can find their own way in the literature, which is growing at an exponential rate.

Up to this moment most of the current research contributions may be characterized as belonging to positive economics. Within this literature the main attention lies at understanding life satisfaction or happiness and thus individuals' preferences with 'life as a whole', with some diversions into health and job satisfaction. The empirical work in this area has focused, for example, on studying individuals' adaptation capacity, their availability to predict future outcomes, and the role of the reference group. This can contribute to a better understanding of individuals' behavior that in turn can be used to predict behavior or to evaluate public policies. For example, although the economic benefits of hosting large sport events seem to be very small, Kavetsos and Szymanski (2010) find evidence in Europe of a positive (although short 
lived) impact on individual happiness of hosting the European or the World Football Cup.

We will now make an attempt to pinpoint what will be the most needed directions for research in the future. Obviously, this is not identical with predicting what will be the most likely directions of research in the near future.

As we said before there is a link between the traditional utility function concept in economics and the satisfaction functions that we are now able to estimate. If we accept only the ordinal character of such functions, then the main novelty of the new approach is that we can estimate indifference curves between a number of non-financial well-being characteristics and money income (or wealth). For example, we can estimate the indifference curves between income and family size, health status, environmental characteristics, level of democracy, and marital quality. From these indifference curves we may estimate the trade-offs and shadow prices in money of all those non-monetary goods. Obviously, at this stage in time all results have to be classified as experimental. A lot of the results have to be confirmed on larger data sets with more variables and more heterogeneous samples. They have also to be re-established over time. But if these results have proved their validity to such an extent that they can be accepted as empirical laws, then the way seems open to use these results for many applications. We think here that results on domain satisfactions will have more applicability than results on satisfaction with life-as-a-whole.

We think of the following applications as lying most at hand:

- The construction of family equivalence scales, usable for tax corrections and social benefits, for divorce cases, and for establishing child almonies.

- Health equivalence scales, which can be used for health litigations, and the construction of QALY-type evaluations of therapies and medicines for cost-benefit analysis,

- Substitution of Willingness to Pay studies by more sophisticated survey methods. It is obvious that most conventional WTP-surveys present an open invitation to strategic response behavior. 
- Results on job satisfaction that can be used for Human Relations policy in firms and the construction of pay schedules, the evaluation of non-monetary perks, overtime, service hours, etc.

- The evaluation of environment and urban living conditions and the trade-offs between them.

If we are willing to assign cardinal significance to our estimated satisfaction function, a much wider world becomes visible. Cardinal significance, as we defined before, means that we assume that the (numerical) evaluations of various utility levels may be understood as equi-distanced on the Cantril ladder. Moreover, such a function is bounded from below and above. ${ }^{1}$ Then a satisfaction function may be described by a distribution function. As income always figures logarithmically in happiness equations, it lies at hand to take a lognormal distribution function as a tractable two-parameter function or the CRRA-function as a one-parameter function. The former function may be seen as a generalization of the latter. In that case the estimated utility functions (domains and life-as-a-whole) may be seen as the classical cardinal utility functions neo-classical economics had removed from the stage, and for which nevertheless economic applied theory is so desperately in need.

It stands to reason that this is still a step further than what has been sketched before. It implies that it is has to be seen as experimental at the moment. It may be that another functional specification yields a better approximation. For cardinal usage the functional specification is much more important than for ordinal usage.

However, if we accept a specific specification as not too far from the average truth, then we can make probability weightings to assess Von Neumann-Morgenstern/Savage utility expectations and accordingly choices under uncertainty and risk can be evaluated. This can then be used to give empirical content to the corresponding decision theory (both financial and non-financial).

\footnotetext{
${ }^{1}$ See also Van Praag (1968) where such assumptions were firstly made.
} 
It then becomes also possible to sum utilities over time in order to assess utility streams over time, giving empirical content to investments over time, lifetime utility of individuals. Obviously the combination of aggregation over time and over uncertain events becomes then available as well. It is obvious that this would also be extremely useful to evaluate the life-time benefits of therapies and medicines in health-and pharmaeconomics.

Finally, we may think then of aggregation of individual utilities over members of society yielding a social welfare function and social welfare inequality measures. Such instruments might then be used for constructing socio-economic policies. This could become a powerful instrument of analysis for long-term socio-economic policy.

Another field of application might be an empirical foundation of equilibrium and game theory by using estimated cardinal utility functions of the players. However, it may be doubted whether estimation of utility functions per individual can be so accurate as to predict behavior of specific individuals with some measure of preciseness.

To us it is manifest that the happiness approach must be seen as a gateway to making economics a more realistic science than in the days when subjective questioning was anathema to orthodox economists (see Robbins, 1932, and others). On the other hand we have to be modest. This new empirical branch of economics, or rather of economics and psychology (Diener and Biswas-Diener, 2009; Kahneman et al., 1999) is still in its infancy. However, we do not doubt that in the coming decades it will become a completely accepted instrument of economic research. 


\section{References}

Alesina, A., R. Di Tella, and R. MacCulloch (2004), 'Inequality and happiness: are Europeans and Americans different?'. Journal of Public Economics 88, 2009-2042.

Angelini, V., D. Cavapozzi, L. Corazzini, and O. Paccagnella (2008), Do Danes and Italians Rate Life Satisfaction in the Same Way? Using Vignettes to Correct for Individual-specific Scale Biases. Mimeo, University of Padua.

Argyle, M. (1987), The Psychology of Happiness. London: Methuen.

Bago d'Uva, T., M. Lindeboom, O. O'Donnell, and E. van Doorslaer (2009), 'Slipping anchor? Testing The Vignettes approach to identification and correction of reporting heterogeneity. Tinbergen Institute Discussion Paper Series. DP 2009-091/3'. forthcoming in Journal of Human Resources.

Bautista, C. C. (2008), 'Subjective poverty thresholds in the Philippines'. Working Paper University of the Philippine.

Blanchflower, D. G. and A. Oswald (2007), 'Is well-being U-shaped over the life cycle?'. NBER Working Paper No. 12935.

Bok, D. (2010), The Politics of Happiness: What Government Can Learn from the New Research on Well-Being. Princeton, US: Princeton University Press. 
Brickman, P. and D. T. Campbell (1971), 'Hedonic relativism and the good society'. In: M. H. Appley (ed.): Adaptation-Level Theory: A symposium. Academic Press.

Brickman, P., D. Coates, and R. Janoff-Bulman (1978), 'Lottery winners and accident victims: Is happiness relative?'. Journal of Personality and Social Psychology 36, 917-927.

Cantril (1965), The Pattern of Human Concern. New Brunswick: Rutgers University Press.

Clark, A. (2001), 'What really matters in a job? Hedonic measurement using quit data'. Labour Economics 8, 223-242.

Clark, A., A. Knabe, and S. Rätzel (2010), 'Boon or bane? Well-being, others' unemployment, and labor-market risk'. Labour Economics $17,52-61$.

Clark, A. E., E. Diener, Y. Georgellis, and R. Lucas (2008), 'Lags and leads in life satisfaction: A test of the baseline hypothesis'. Economic Journal 118, F222-F243.

Clark, A. E. and C. Senik (2010), 'Who compares to whom? The anatomy of income comparisons in Europe'. The Economic Journal, forthcoming.

Colosanto, D., A. Kapteyn, and J. V. D. Gaag (1984), 'Two subjective definitions of poverty: Results from the Wisconsin basic needs study'. Journal of Human Resources 19, 127-137.

Daly, M. C. and D. J. Wilson (2011), 'Relative status and well-being: Evidence from U.S. suicide deaths'. Review of Economics and Statistics, forthcoming.

De Lora, E., A. Powell, B. M. S. Van Praag, and P. Sanguinetti (eds.) (2010), The Quality of Life in Latin American Cities: Markets and Perception. World Bank Publications.

Deaton, A. (2008), 'Income, health, and well-being around the world: Evidence from the gallup world poll'. Journal of Economic Perspectives 22, 53-72.

Debreu, G. (1959), Theory of Value. New York: Wiley.

Delaney, L., C. Newman, and B. Nolan (2006), 'Reference dependent financial satification over the course of the celtic tiger: A panel analysis utilising the living in ireland survey 1994-2001'. Working Papers 2006-09, Geary Institute, University College Dublin. 
Delaney, L., C. Newman, and B. Nolan (2008), 'A dynamic model of the relationship between income and financial satisfaction'. Economic and Social Review 39, 105-130.

Di Tella, R. and R. MacCulloch (2008), 'Gross national happiness as an answer to the Easterlin paradox?'. Journal of Development Economics 86, 22-42.

Di Tella, R., R. J. MacCulloch, and A. J. Oswald (2001), 'Preferences over inflation and unemployment: Evidence from surveys of happiness'. The American Economic Review 91, 335-341.

Di Tella, R., R. J. MacCulloch, and A. J. Oswald (2003), 'The macroeconomics of happiness'. Review of Economics and Statistics 85, 809-827.

Diener, E. and R. Biswas-Diener (2009), Happiness: Unlocking the Mysteries of Psychological Wealth. Oxford, UK: Blackwell Publishing Ltd.

Diener, E. and R. E. Lucas (1999), 'Personality and subjective wellbeing'. In: D. Kahneman, E. Diener, and N. Schwarz (eds.): WellBeing: The Foundations of Hedonic Psychology. New York: Russell Sage Foundation. Chapter 11.

Diener, E., E. M. Suh, R. E. Lucas, and H. L. Smith (1999), 'Subjective well-being: Three decades of progress'. Psychological Bulletin 125, 276-302.

Easterlin, R. A. (1974), 'Does economic growth improve the human lot? Some empirical evidence'. In: P. A. David and M. W. Reder (eds.): Nations and Households in Economic Growth. Essays in Honor of Moses Abramowitz. NY: Academic Press, pp. 89-125.

Easterlin, R. A. and O. Sawangfa (2009), 'Happiness and domain satisfaction: New directions for the economics of happiness'. In: A. K. Dutt and B. Radcliff (eds.): Happiness, Economics and Politics: Towards A Multi-Disciplinary Approach. US: University of Notre Dame.

Edgeworth, F. Y. (1881), Mathematical Psychics, An Essay on the Application of Mathematics to the Moral Sciences.

Feldman, F. (2010), What is This Thing Called Happiness? A Philosophical Study of the Nature and Value of Happiness. Oxford, UK: Oxford University Press. 
Ferrer-i-Carbonell, A. (2005), 'Income and well-being: An empirical analysis of the comparison income effect'. Journal of Public Economics 89, 997-1019.

Ferrer-i-Carbonell, A. and P. Frijters (2004), 'How important is methodology for the estimates of the determinants of happiness?'. The Economic Journal 114, 641-659.

Ferrer-i-Carbonell, A. and B. M. S. van Praag (2001), 'Poverty in the Russian Federation'. Journal of Happiness Studies 2, 147-172.

Ferrer-i-Carbonell, A. and B. M. S. Van Praag (2002), 'The subjective costs of health losses due to chronic diseases. An alternative model for monetary appraisal'. Health Economics 11, 709-722.

Ferrer-i-Carbonell, A., B. M. S. Van Praag, and I. Theodossiou (2010), 'A New Look at Vignette Equivalence and Response Consistency with an Application to Job Satisfaction'. Working Paper.

Fleurbaey, M. (2008), 'Economics and economic justice'. In: Stanford Encyclopedia of Philosophy. http://plato.stanford.edu/entries/ economic-justice/.

Freeman, R. B. (1978), 'Job satisfaction as an economic variable'. The American Economic Review 68, 135-141.

Frey, B. S. (2008), Happiness: A Revolution in Economics. Cambridge, MA London, UK: MIT Press.

Frey, B. S., S. Luechinger, and A. Stutzer (2010), 'The life satisfaction approach to environmental valuation'. Annual Review of Resource Economics 2, 139-160.

Frey, B. S. and A. Stutzer (2002), Happiness and Economics. How the Economy and Institutions Affect Well-being. Princeton: New Jersey: Princeton University Press.

Frijters, P. (2000), 'Do individuals try to maximize general satisfaction?'. Journal of Economic Psychology 21, 281-304.

Frijters, P., J. P. Haisken-Denew, and M. A. Shields (2004), 'Money does matter! Evidence from increasing real income and life satisfaction in East Germany following reunification'. American Economic Review 94, 730-740.

Frijters, P., D. Johnson, and M. A. Shields (2011a), 'Happiness dynamics with quarterly life event data'. Scandinavian Journal of Economics, forthcoming. 
Frijters, P., M. A. Shields, and J. P. Haisken-DeNew (2011b), 'Socioeconomic status, health shocks, life satisfaction and mortality: Evidence from an increasingly mixed proportional hazard model'. Journal of Business and Economic Statistics, forthcoming.

Frijters, P. and B. M. S. Van Praag (1998), 'The effects of climate on welfare and well-being in Russia'. Climatic Change 39, 61-81.

Gardner, J. and A. J. Oswald (2007), 'Money and mental wellbeing: A longitudinal study of medium-sized lottery wins'. Journal of Health Economics 26, 49-60.

Goedhart, T., V. Halberstadt, A. Kapteyn, and B. M. S. Van Praag (1977), 'The poverty line: concept and measurement'. Journal of Human Resources 12, 503-520.

Graham, C. (2009), Happiness Around the World: The Paradox of Happy Peasants and Miserable Millionaires. Oxford, UK: Oxford University Press.

Graham, C. and A. Felton (2006), 'Inequality and happiness: Insights from Latin America'. Journal of Economic Inequality 4, 107-122.

Green, P. E. and V. Srinivasan (1978), 'Conjoint analysis in consumer research: issues and outlook'. Journal of Consumer Research 5, 103-123.

Grosfeld, I. and C. Senik (2010), 'The emerging aversion to inequality: Evidence from Poland 1992-2005'. Economics of Transition 18, $1-26$.

Gustafsson, B., L. Shi, and H. Sato (2004), 'Can subjective poverty line be applied to China? Assessing poverty among urban residents in 1999'. Journal of International Development 16, 1089-1107.

Guven, C., C. Senik, and H. Stichnoth (2010), 'You can't be happier than your wife. Happiness gaps and divorce'. IZA Discussion Paper No. 4599, Bon.

Hagenaars, A. (1987), 'A class of poverty indices'. International Economic Review 28, 583-607.

Hagenaars, A. J. M. (1986), The perception of poverty. The Netherlands: North Holland and Elsevier publ.cy.

Haybron, D. M. (2010), The Pursuit of Unhappiness: The Elusive Psychology of Well-Being. Oxford University Press. 
Headey, B. and A. Wearing (1989), 'Personality, life events, and subjective well-being: Toward a dynamic equilibrium model'. Journal of Personality and Social Psychology 57, 731-739.

Helliwell, J. F. (2007), 'Well-being and social capital: Does suicide pose a puzzle?'. Social Indicators Research 81, 455-496.

Houthakker, H. S. (1950), 'Revealed preference and the utility function'. Economica 17, 159-174.

Jones, M. P. (1996), 'Indicator and stratification methods for missing explanatory variables in multiple linear regression'. Journal of the American Statistical Association 91, 222-230.

Kahneman, D. (1999), 'Objective happiness'. In: D. Kahneman, E. Diener, and N. Schwarz (eds.): Foundations of Hedonic Psychology: Scientific Perspectives on Enjoyment and Suffering. New York, Chapter 1: Russell Sage Foundation.

Kahneman, D., E. Diener, and N. Schwarz (eds.) (1999), Foundations of Hedonic Psychology: Scientific Perspectives on Enjoyment and Suffering. New York: Russell Sage Foundation.

Kahneman, D. and A. B. Krueger (2006), 'Developments in the measurement of subjective well-being'. Journal of Economic Perspectives 20, 3-24.

Kahneman, D., A. B. Krueger, and D. Schkade (2006), 'Would you be happier if you were richer? A focusing illusion'. Science 312, 19081910.

Kahneman, D., A. B. Krueger, D. Schkade, N. Schwarz, and A. Stone (2004), 'The Day Reconstruction Method (DRM): Instrument Documentation'. http://sitemaker.umich.edu/norbert.schwarz/files/ drm_documentation_july_2004.pdf.

Kahneman, D., P. P. Wakker, and R. Sarin (1997), 'Back to bentham? Explorations of experienced utility'. The Quarterly Journal of Economics 112, 375-405.

Kalmijn, W. and R. Veenhoven (2005), 'Measuring inequality of happiness in nations: In search for proper statistics'. Journal of Happiness Studies 6, 357-396.

Kapteyn, A., J. P. Smith, and A. van Soest (2007), 'Vignettes and selfreports of work disability in the US and the Netherlands'. American Economic Review 97, 461-473. 
Kapteyn, A., J. P. Smith, and A. Van Soest (2010), 'Life satisfaction'. In: E. Diener, J. F. Helliwell, and D. Kahneman (eds.): International Differences in Well-Being. Chapter 4 Oxford University Press.

Kapteyn, A. and F. G. Van Herwaarden (1980), 'Interdependent welfare functions and optimal income distribution'. Journal of Public Economics 14, 375-397.

Kapteyn, A., B. M. S. Van Praag, and F. G. Van Herwaarden (1978), 'Individual welfare functions and social reference spaces'. Economics Letters 1, 173-177.

Kapteyn, A., T. Wansbeek, and J. Buyze (1979), 'Maximizing or satisficing'. The Review of Economics and Statistics 61(4), 549-563.

King, G., C. J. L. Murray, J. Salomon, and A. Tandon (2004), 'Enhancing the validity and crosscultural comparability of measurement in survey research'. American Political Science Review 98, 184-191.

Kuhn, P. J., P. A. Kooreman, R. Soetevent, and A. Kapteyn (2011), 'The own and social effects of an unexpected income shock: Evidence from the dutch postcode lottery'. NBER Working Paper no. 14305 (May 2008). American Economic Review, forthcoming.

Larsen, R. J. (2000), 'Towards a science of mood regulation'. Psychological Inquiry 11, 129-141.

Layard, R. (2005), Happiness: Lessons from a New Science. London: Penguin Books.

Louviere, J. J., D. A. Hensher, and J. D. Swait (2000), Stated Choice Methods: Analysis and Application. Cambridge University Press.

Lucas, E. R., A. Clark, Y. Georgellis, and E. Diener (2004), 'Unemployment alters the set-point for life satisfaction'. Psychological Science 15, 8-13.

Lucas, R. E. and U. Schimmack (2009), 'Income and well-being. How big is the gap between the rich and the poor?'. Journal of Research in Personality 43, 75-78.

Luechinger, S. (2009), 'Valuing air quality using the life satisfaction approach'. Economic Journal 119, 482-515.

Luttmer, E. (2005), 'Neighbors as negatives: Relative earnings and wellbeing'. Quarterly Journal of Economics 120, 963-1002.

Lykken, D. and A. Tellegen (1996), 'Happiness is a stochastic phenomenon'. Psychological Siente 7, 186-189. 
Lyubomirsky, S. (2001), 'Why are some people happier than others? The role of cognitive and motivational processes in well-being'. American Psychologist 56, 239-249.

Maddala, G. S. (1983), Limited-Dependent and Qualitative Variables in Econometrics. Cambridge, UK: Cambridge University Press.

Mayraz, G., G. G. Wagner, and J. Schupp (2009). Life Satisfaction and Relative Income: Perceptions and Evidence. IZA DP No. 4390.

Metcalfe, R., N. Powdthavee, and P. Dolan (2011), 'Destruction and distress: Using a quasi-experiment to show the effects of the September 11 attacks on subjective well-being in the UK'. Economic Journal, forthcoming.

Mundlak, Y. (1978), 'On the pooling of time series and cross section data'. Econometrica 46, 69-85.

Myers, D. G. (1993), 'Pursuing happiness'. Psychology Today pp. 32-35, 66-67.

Nerlove, M. (1995), 'Hedonic price functions and the measurement of preferences: The case of Swedish wine consumers'. European Economic Review 39, 1697-1716.

Nussbaum, M. C. and A. Sen (1993), The Quality of Life. Oxford: Clarendon Press.

Oswald, A. J. and N. Powdthavee (2008), 'Death, happiness, and the calculation of compensatory damages'. Journal of Legal Studies 37, S217-S252.

Oswald, A. J., E. Proto, and D. Sgroi, (2009). Happiness and productivity, IZA Discussion Paper No. 4645, Bon.

Oswald, A. J. and S. Wu (2011), 'Well-being across America: evidence from a random sample of one million U.S. citizens'. Review of Economics and Statistics, forthcoming.

Ott, J. (2005), 'Level and inequality of happiness in nations: Does greater happiness of a greater number imply greater inequality in happiness?'. Journal of Happiness Studies 6, 397-420.

Parducci, A. (1995), Happiness, Pleasure, and Judgment: The Contextual theory and its applications. Mahwah, NJ: Lawrence Erlbaum Associates.

Pareto, V. (1909), Manuel d'économie politique. Paris: Giard \& E. Brière. 
Pischke, J.-S. (2010), Money and Happiness: Evidence from the Industry Wage Structure. Manuscript. London School of Economics.

Plug, E. J. S. and B. M. S. Van Praag (1995), 'Family equivalence scales within a narrow and broad welfare context'. Journal of Income Distribution 4, 171-186.

Pouliakas, K. and I. Theodossiou (2010), 'Socio-economic differences in the satisfaction of high-pay and low-pay jobs in Europe'. International Labour Review 1.

Powdthavee, N. (2010), 'How much does money really matter? Estimating the causal effects of income on happiness'. Empirical Economics 39, 77-92.

Pradhan, M. and M. Ravallion (2000), 'Measuring poverty using qualitative perceptions of consumption adequacy'. Review of Economics and Statistics 82, 462-471.

Rehdanz, K. and D. Maddison (2005), 'Climate and happiness'. Ecological Economics 52, 111-125.

Roback, J. (1982), 'Wages, rents and the quality of life'. Journal of Political Economic 90, 1257-1278.

Robbins, L. (1932), An Essay on the Nature and Significance of Economic Science. London: MacMillan.

Robbins, L. (1938), 'Interpersonal comparisons of utility: A comment'. Economic Journal 48, 635-641.

Rosen, S. (1974), 'Hedonic princes and implicit markets: Product differentiation in pure competition'. Journal of Political Economic 82, $34-55$.

Sacks, D. W., B. Stevenson, and J. Wolfers (2010). Subjective wellbeing, income, economic development and growth. CEPR Discussion Paper No. DP8048.

Samuelson, P. (1974), 'Complementarity: An essay on the 40th anniversary of the Hicks-Allen revolution in demand theory'. Journal of Economic Literature 69, 255-289.

Samuelson, P. A. (1947), Foundations of Economic Analysis. Harvard University Press.

Sandvik, E., E. Diener, and L. Seidlitz (1993), 'Subjective well-being: The convergence and stability of self-report and non-self-report measures'. Journal of Personality 61, 317-342. 
Schimmack, U., E. Diener, and S. Oishi (2002), 'Life-satisfaction is a momentary judgment and a stable personality characteristic: The use of chronically accessible and stable sources'. Journal of Personality 70, 345-384.

Schwartz, B., A. Ward, J. Monterosso, S. Lyubomirsky, K. White, and D. R. Lehman (2002), 'Maximizing versus satisficing: Happiness is a matter of choice'. Journal of Personality and Social Psychology 83, 1178-1197.

Senik, C. (2004), 'When information dominates comparison: Learning from Russian subjective panel data'. Journal of Public Economics 88, 2099-2123.

Simon, H. A. (1955), 'A behavioral model of rational choice'. Quarterly Journal of Economics 59, 99-118.

Smyth, R. and X. Qian (2008), 'Inequality and happiness in Urban China'. Economics Bulletin 4, 1-10.

Stevenson, B. and J. Wolfers (2008a), 'Economic growth and happiness: Reassessing the easterlin paradox'. Brookings Papers on Economic Activity Spring 2008, 1-87.

Stevenson, B. and J. Wolfers (2008b), 'Economic growth and subjective well-being: Reassessing the Easterlin paradox'. Brookings Papers on Economic Activity Spring 2008, 1-102.

Stevenson, B. and J. Wolfers (2008c), 'Happiness inequality in the United States'. Journal of Legal Studies 37, S33-S79.

Stewart, A. L., R. D. Hays, and J. E. Ware, Jr (1988), 'The MOS short-form general health survey. Reliability and validity in a patient population'. Medical Care 26, 724-735.

Stutzer, A. (2004), 'The role of income aspirations in individual happiness'. Journal of Economic Behavior and Organization 54, 89-109.

Van Beek, K. W. H., C. C. Koopmans, and B. M. S. Van Praag (1997), 'Shopping at the labour market: A real tale of fiction'. European Economic Review 41, 295-317.

Van de Stadt, H., A. Kapteyn, and S. Van de Geer (1985), 'The relativity of utility: Evidence from panel data'. Review of Economics and Statistics 67, 179-187. 
Van Ophem, H., P. Stam, and B. M. S. Van Praag (1999), 'Multichoice logit: Modeling incomplete preference rankings of classical concerts'. Journal of Business and Economic Statistics 17, 117-128.

Van Praag, B. M. S. (1968), Individual Welfare Functions and Consumer Behavior: A Theory of Rational Irrationality, North-Holland Publishing Company. The Netherlands: Amsterdam.

Van Praag, B. M. S. (1971a), Individual Welfare Functions and Consumer Behavior - A Theory of Rational Irrationality. Dissertation, Contributions to Economic Analysis, nr. 57: North-Holland Publishing Company, Amsterdam.

Van Praag, B. M. S. (1971b), 'The welfare function of income in Belgium: An empirical investigation'. European Economic Review 2, 337-369.

Van Praag, B. M. S. (1976), 'The individual welfare function of income and its offspring'. In: J. S. Cramer, A. Heertje, and P. Venekamp (eds.): Relevance and Precision. Essays in honour of Pieter de Wolff, Amsterdam: North-Holland Publish Company.

Van Praag, B. M. S. (1981), 'Reflections on the theory of individual welfare functions. Report 81.14, Centre for Research in Public Economics, Leyden University'. Proceedings of the American Statistical Association.

Van Praag, B. M. S. (1988a), 'Climate equivalence scales: an application of a general method'. European Economic Review 2, 337-369.

Van Praag, B. M. S. (1988b), 'Memory and Anticipation processes and their significance for social security and income inequality'. In: S. Maital (ed.): Applied Behavioural Economics. pp. 731-751.

Van Praag, B. M. S. (1991), 'Ordinal and cardinal utility: An integration of the two dimensions of the welfare concept'. Journal of Econometrics 50, 69-89.

Van Praag, B. M. S. (2010), 'Well-being inequality and reference groups: An agenda for new research'. IZA Discussion Papers 4727, Bonn.

Van Praag, B. M. S. and B. Baarsma (2005), 'Using happiness surveys to value intangibles: The case of airport noise'. Economic Journal 115, 224-246. 
Van Praag, B. M. S., S. Dubnoff, and N. L. Van Der Sar (1988), 'On the measurement and explanation of standards with respect to income, age and education'. Journal of Economic Psychology 8, 481-498.

Van Praag, B. M. S. and A. Ferrer-i-Carbonell, (2001). Agedifferentiated QALY losses. IZA Discussion paper No. 314. Available at SSRN: http://ssrn.com/abstract $=273337$.

Van Praag, B. M. S. and A. Ferrer-i-Carbonell (2004), Happiness Quantified: A Satisfaction Calculus Approach. Oxford: UK: Oxford University Press.

Van Praag, B. M. S. and A. Ferrer-i-Carbonell (2008a), Happiness Quantified: A Satisfaction Calculus Approach. Oxford: UK. Revised \& Paperback edition: Oxford University Press.

Van Praag, B. M. S. and A. Ferrer-i-Carbonell (2008b), 'A multidimensional approach to subjective poverty'. In: N. Kakwani and J. Silber (eds.): Quantitative Approaches to Multidimensional Poverty Measurement. Chapter 8. NY: Palgrave, macmillan.

Van Praag, B. M. S., P. Frijters, and A. Ferrer-i-Carbonell (2003), 'The anatomy of subjective well-being'. Journal of Economic Behavior and Organization 51, 29-49.

Van Praag, B. M. S., T. Goedhart, and A. Kapteyn (1980), 'The poverty line: A pilot survey in Europe'. The Review of Economics and Statistics 62, 461-465.

Van Praag, B. M. S. and A. Kapteyn (1973), 'Further evidence on the individual welfare function of income: An empirical investigation in the Netherlands'. European Economic Review 4, 33-62.

Van Praag, B. M. S., D. Romanov, and A. Ferrer-i-Carbonell (2010), 'Happiness and financial satisfaction in israel. Effects of religiosity, ethnicity, and war'. Journal of Economic Psychology, forthcoming.

Voǒková, H. and P. Hullegie (2010), 'Is the anchoring vignettes method sensitive to the domain and choice of the vignette?'. Netspar Discussion Paper 01/2010-004.

Ware, J. E. and C. D. Sherboune (1992), 'The MOS 36-item short-form health survey (SF-36): I. Conceptual framework and item selection'. Medical Care 30, 473-483. 
White, M. and P. Dolan (2009), 'Accounting for the richness of daily activities'. Psychological Science 20, 1000-1008.

Williams, D. E. and J. K. Thompson (1993), 'Biology and behavior: A set-point hypothesis of psychological functioning'. Behavior Modification 17, 43-57. 